\title{
Integrating adverse effect analysis into environmental risk assessment for exotic generalist arthropod biological control agents: a three-tiered framework
}

\author{
Débora P. Paula (1) David A. Andow • Barbara I. P. Barratt - Robert S. Pfannenstiel • \\ Philippa J. Gerard · Jacqui H. Todd · Tania Zaviezo • Maria G. Luna • \\ Claudia V. Cédola - Antoon J. M. Loomans - Andy G. Howe - Michael D. Day • \\ Clark Ehlers • Chris Green - Salvatore Arpaia • Eizi Yano • Gabor L. Lövei • \\ Norihide Hinomoto $\cdot$ Eliana M. G. Fontes - Carmen S. S. Pires • Pedro H. B. Togni • \\ James R. Nechols • Micky D. Eubanks • Joop C. van Lenteren
}

Received: 1 May 2020/Accepted: 23 September 2020

(C) International Organization for Biological Control (IOBC) 2020

\begin{abstract}
Environmental risk assessments (ERAs) are required before utilizing exotic arthropods for biological control (BC). Present ERAs focus on exposure analysis (host/prey range) and have resulted in approval of many specialist exotic biological control agents (BCA). In comparison to specialists, generalist arthropod BCAs (GABCAs) have been considered inherently risky and less used in classical
\end{abstract}

Débora. P. Paula and David A. Andow contributed equally to the study.

Handling Editor: Eric Wajnberg

Electronic supplementary material The online version of this article (https://doi.org/10.1007/s10526-020-10053-8) contains supplementary material, which is available to authorized users.

D. P. Paula $(\varangle)$ · E. M. G. Fontes · C. S. S. Pires

Department of Biological Control, Embrapa Genetic

Resources and Biotechnology, Brasília,

DF 70770-901, Brazil

e-mail: debora.pires@embrapa.br

D. A. Andow

Department of Entomology, University of Minnesota, 219

Hodson Hall, St. Paul, MN 55108, USA

B. I. P. Barratt

AgResearch, Invermay Research Centre,

PB 50034, Mosgiel, New Zealand biological control. To safely consider exotic GABCAs, an ERA must include methods for the analysis of potential effects. A panel of 47 experts from 14 countries discussed, in six online forums over 12 months, scientific criteria for an ERA for exotic GABCAs. Using four case studies, a three-tiered ERA comprising Scoping, Screening and Definitive Assessments was developed. The ERA is primarily based on expert consultation, with decision processes in each tier that lead to the approval of the petition or the subsequent tier. In the Scoping Assessment, likelihood of establishment (for augmentative BC), and potential effect(s) are qualitatively assessed. If risks are identified, the Screening Assessment is conducted, in which 19 categories of effects (adverse and beneficial) are quantified. If a risk exceeds the proposed risk threshold in any of these categories, the analysis

\section{B. I. P. Barratt · J. H. Todd}

Better Border Biosecurity, Wellington, New Zealand

R. S. Pfannenstiel

Pests, Pathogens and Biocontrol Permitting, Plant Health Programs, USDA APHIS PPQ, 4700 River Road, Unit 133, Riverdale, MD 20737, USA

P. J. Gerard

AgResearch, Ruakura Research Centre,

PB 3123 Hamilton, New Zealand 
moves to the Definitive Assessment to identify potential non-target species in the respective category(ies). When at least one potential non-target species is at significant risk, long-term and indirect ecosystem risks must be quantified with actual data or the petition for release can be dismissed or withdrawn. The proposed ERA should contribute to the development of safe pathways for the use of low risk GABCAs.

Keywords Augmentative - Biocontrol - Biosafety · Classical $\cdot$ Invertebrates $\cdot$ Non-target species

\section{Introduction}

There is a worldwide demand to reduce pesticide use in crop production (e.g., van Lenteren et al. 2018) in which biological control (BC) has been a key component through conservation, classical and augmentation BC. Conservation BC implements practices that enhance pre-existing natural enemies. Classical BC introduces an exotic biological control agent (BCA) into a new environment with the expectation that it will establish and provide long term control of an exotic pest, while augmentative $\mathrm{BC}$ programs release a BCA (native, naturalized or exotic) into a localized

\section{J. H. Todd}

The New Zealand Institute for Plant and Food Research Limited, Private Bag 92169, Auckland 1142, New

Zealand

T. Zaviezo

Facultad Agronomía e Ing. Forestal, Pontificia

Universidad Católica de Chile, Santiago, Chile

M. G. Luna - C. V. Cédola

CEPAVE (CONICET - UNLP), Boulevard 120 entre 60 y

64, 1900 La Plata, Argentina

A. J. M. Loomans

National Plant Protection Organization (NPPO),

Netherlands Food and Consumer Product Safety

Authority (NVWA), Geertjesweg 15,

6706 EA Wageningen, The Netherlands

A. G. Howe

Department of Geosciences and Natural Resource Management, University of Copenhagen, Rolighedsvej

23, 1958 Frederiksberg C, Denmark area to attain short-term control of a pest. Conservation $\mathrm{BC}$ has a large unrealized potential throughout the world (Wyckhuys et al. 2013) and does not require an environmental risk assessment (ERA). Therefore, because classical and augmentative BC (using exotic BCAs) require an ERA due to their potential for causing environmental harm, they are only justified when the local natural enemies do not provide sufficient control.

Due to the recognized non-target effects caused by the historical releases of exotic generalist arthropod biological control agents (GABCAs), arthropod BC has been largely restricted since the 1950s to the use of specialist natural enemies because they have a narrow host range (e.g., Nechols et al. 1992; van Lenteren et al. 2020). More recently, heightened concerns over non-target effects have resulted in an even greater concentration on specialist natural enemies and partly explains the lower number of introductions worldwide since the 1990s (Cock et al. 2016). Even though generalist and specialist BCAs have resulted in many outstanding successes (Cock et al. 2016), specialists continue to be favored today. Thus, expanding the scope of biological control to enable the consideration of GABCAs could increase the value of biological control worldwide. For example, several pests have no suitable specialist natural enemies, or their natural

\section{A. G. Howe}

Forest Industries Research Centre, University of the Sunshine Coast, GPO Box 267, Brisbane, QLD 4001, Australia

M. D. Day

Department of Agriculture and Fisheries,

GPO Box 267, Brisbane, QLD 4001, Australia

C. Ehlers

Environmental Protection Authority, Level 10, 215

Lambton Quay, Wellington 6011, New Zealand

C. Green

Department of Conservation,

Private Bag 68908, Newton, Auckland 1145, New

Zealand

S. Arpaia

Division Bioenergy, Biorefinery and Green Chemistry, ENEA Research Centre Trisaia, S.S. 106 Jonica km 419.5, 75026 Rotondella, MT, Italy 
enemies are difficult to rear or exert insufficient biological control (Nechols et al. 1992). In contrast to classical BC introductions, there has been a marked shift towards considering GABCAs for augmentative $\mathrm{BC}$ in greenhouse production (e.g., van Lenteren 2012). Nevertheless, the use of exotic GABCAs has been handicapped by a few problematic releases (Cock et al. 2016), substantial data gaps on existing and potential GABCAs, and the lack of suitable and acceptable ERA methodology for regulatory bodies and $\mathrm{BC}$ practitioners.

ERA methodologies have been developed to ensure the safe use of exotic BCAs (e.g., van Lenteren et al. 2003, 2006; EPPO 2018). These favor specialist BCAs by using methods that regard the use of generalist natural enemies as too risky (Bigler et al. 2006; van Lenteren et al. 2006). Based on species biology and ecology, van Lenteren et al. (2006) proposed a tiered scoping assessment, which relied on a determination that the BCA had a low likelihood of establishment and a narrow host/prey range, to rapidly identify BCAs with low environmental risk. In EPPO (2018), the first tier is an Express Environmental Impact Assessment (EIA), which poses three questions. In the subsequent Full EIA of the EPPO (2018) schema, the applicant is requested to address several issues related to nontarget effects using qualitative scores, all of which can be answered with much greater certainty for specialist BCAs. These approaches eliminate from consideration most exotic generalist natural enemies as BCAs, even ones that are unlikely to cause significant harm to non-target species (Lynch et al. 2001; Andreassen et al. 2009). GABCAs vary significantly in diet

\section{E. Yano}

Center for Ecological Research (CER), Kyoto University, Hirano 2-509-3, Otsu, Shiga 520-2113, Japan

\section{G. L. Lövei}

Department of Agroecology, Aarhus University, Flakkebjerg Research Centre, Forsøgsvej 1, 4200 Slagelse, Denmark

N. Hinomoto

Laboratory of Ecological Information, Graduate School of Agriculture, Kyoto University, Kyoto 606-8502, Japan

P. H. B. Togni

Departamento de Ecologia, Universidade de Brasília (UnB), Campus Universitário Darcy Ribeiro, Brasília, DF 70910-900, Brazil breadth, habitat use, and their interactions with other species, yet diet breadth is poorly known for many of them, especially predatory arthropod species in their natural habitats. For example, unexpected oligophagy of some generalist predators has been demonstrated by molecular gut content analysis (e.g., Paula et al. 2016). Initial steps toward a full spectrum ERA have focused on methods to better predict host/prey range of generalists. These include semi-quantitative ranking methods to determine the species most "at risk" in the receiving environment (Todd et al. 2015; Barratt et al. 2016) and methods to identify species that might be harmed by competition from BCAs (McGrath et al. 2020).

To assess risks of exotic GABCAs, a comprehensive ERA should include adverse effects analysis, which at present is rudimentary (e.g., NAPPO 2015; EPPO 2018; etc.). The present focus on host/prey range testing identifies non-targets that could be adversely affected, but it does not always address the critical questions of whether the BCA is likely to have an adverse effect on the non-target and to what degree. Consequently, two major scientific issues must be addressed: criteria for determining the potential for harmful/adverse effects and for identifying non-target species/communities/ecosystem processes most at risk, and methods and models for conducting effects analysis. In addition, a harmonized ERA methodology that can be used for any BCA, including exotic GABCAs, is also needed as the existing guidelines and regional agreements (e.g., FAO, NAPPO, EPPO) have not prevented unintended spread of exotic BCAs across borders (Petit et al. 2009; Stahl et al. 2019).

\author{
J. R. Nechols \\ Department of Entomology, Kansas State University, 123 \\ Waters Hall, 1603 Old Claflin Place, Manhattan, \\ KS 66506, USA \\ M. D. Eubanks \\ Department of Entomology, Texas A\&M University, \\ TAMU 2475, College Station, TX 77843-2475, USA \\ J. C. van Lenteren \\ Laboratory of Entomology, Department of Plant Sciences, \\ Wageningen University and Research (WUR), \\ PO Box 16, 6700 AA Wageningen, The Netherlands
}


To enable consideration of the untapped potential for the safe use of generalists, we propose a threetiered ERA (Scoping, Screening and Definitive Assessments) building on previous methods to improve and develop criteria to evaluate the biosafety of any exotic GABCA and other BCAs. In this work, exposure analysis (host/prey range assessment) is complemented with effects analysis (potential effects assessment). With the structured use of the "best available information" in this ERA, we aim to support regulation of exotic GABCAs and sensitize the broader scientific community and stakeholders regarding the knowledge gaps that are impeding the continued improvement of ERA methodologies for the safe use of exotic GABCAs.

\section{Expert panel working group}

The three-tiered ERA for exotic GABCAs was developed by a multidisciplinary expert panel of specialists and stakeholders, during a 12 month process (2018-2019) of structured online discussions, culminating in a public symposium and workshop. An organizing committee, composed of experts from four countries (Brazil, New Zealand, The Netherlands and USA, see Supplementary Material), formed the panel and guided the online discussions. Professionals with expertise in biological control, ecology, invasive species, regulation, risk assessment and species conservation, from academia, government and industry were invited without financial incentive. Sixty-six experts from 14 countries accepted the invitation. Forty-seven experts participated at least once (see Supplementary Material), and 28 experts from 14 countries participated in at least three of the six forums. The forum summary reports 1 to 3 and 6 can be provided upon request to the corresponding author. Summary reports 4 and 5 are provided in Supplementary Material.

\section{Online discussion forums}

The six online discussions were held in English during two weeks every other month from November 2018 to November 2019 using the JotForm platform (https:// www.jotform.com/) accessed by individual private links. The Delphi method (Sackman 1974) was used with anonymous participation, except for the co-chairs of the organizing committee. Forum materials presented background information about discussion topics, framing and providing case studies to instantiate the issues (Table 1). At the end of the six online discussions, the workshop Using Generalist arthropod biological control agents: Ensuring effectiveness and safety was organized at the 2019 annual meeting of the Entomological Society of America in Saint Louis, Missouri, USA, attracting 50 participants from industry, academia and regulatory agencies to discuss remaining topics that needed more thorough consideration.

\section{The proposed comprehensive environmental risk assessment}

The proposed three-tiered ERA serves as a structure for a petition for an exotic GABCA (Fig. 1). The first tier is a Scoping Assessment which aims to determine if the exotic GABCA can be considered 'highly unlikely to have an adverse effect' or if further risk assessment steps are needed. The second tier is a Screening Assessment, which is only required when the Scoping Assessment determines that an exotic GABCA needs additional assessment. The aim of this tier is to identify the most prominent potential adverse effects associated with the exotic GABCA and the likelihood and magnitude of these effects to determine which, if any, merit a definitive assessment. The last tier is the Definitive Assessment and is only needed when the Screening Assessment determines that additional assessment is needed. The first two tiers are heavily based on expert consultation, while the last tier is based on expert consultation and on data to be provided. Depending on the number and complexity of the identified potentially significant adverse effects, at any point in the three-tiered ERA process, an applicant may choose to withdraw the petition and avoid additional costs. Throughout the methodology, additional details (e.g., number of specimens to be evaluated by a taxonomist, whether the exotic GABCA is evaluated as a population or species, etc.) could be determined by whomever may adapt the methodology. In addition, because regulatory frameworks and authorities vary considerably around the world, we have not specified who would be responsible for the costs and procedures in the ERA, such as 
Table 1 Case studies used in the online discussions on criteria for environmental risk assessment of exotic generalist arthropod biological control agents

\begin{tabular}{|c|c|c|c|c|c|}
\hline Species & Function & Native region & Introduced areas & $\begin{array}{l}\text { Rationale for case } \\
\text { study }\end{array}$ & References \\
\hline $\begin{array}{l}\text { Amblyseius } \\
\text { swirskii (Athias } \\
\text { Henriot, 1962) } \\
\text { (Acarina: } \\
\text { Phytoseiidae) }\end{array}$ & $\begin{array}{l}\text { Predatory mite sold } \\
\text { commercially in } \\
\text { Europe and North } \\
\text { America for } \\
\text { augmentative } \\
\text { biological control in } \\
\text { greenhouse and } \\
\text { nursery crops }\end{array}$ & $\begin{array}{l}\text { Eastern } \\
\text { Mediterranean } \\
\text { region }\end{array}$ & $\begin{array}{l}\text { USA in } 1983 \\
\text { and released } \\
\text { or tested since } \\
2005 \text { in parts } \\
\text { of the Asia, } \\
\text { Africa and } \\
\text { Argentina }\end{array}$ & $\begin{array}{l}\text { Permit declined in } \\
\text { Brazil in } 2018 \text { for } \\
\text { commercial use as } \\
\text { augmentative BCA } \\
\text { in greenhouse } \\
\text { production due to a } \\
\text { lack of an ERA in } \\
\text { the country }\end{array}$ & $\begin{array}{l}\text { Arthurs et al. (2009), } \\
\text { Cédola and Polack } \\
\text { (2011), Kade et al. } \\
\text { (2011), Sato and } \\
\text { Mochizuki (2011), } \\
\text { EPPO (2020) }\end{array}$ \\
\hline $\begin{array}{l}\text { Fopius arisanus } \\
\text { (Sonan, 1932), } \\
\text { (Hymenoptera: } \\
\text { Braconidae) }\end{array}$ & $\begin{array}{l}\text { Solitary egg-larval } \\
\text { parasitoid of fruit- } \\
\text { feeding Tephritidae }\end{array}$ & Southeast Asia & $\begin{array}{l}\text { Several } \\
\text { countries in } \\
\text { Oceania, } \\
\text { Borneo, India, } \\
\text { Malaysia, } \\
\text { Taiwan, } \\
\text { Thailand, } \\
\text { Guinea, } \\
\text { Guatemala }\end{array}$ & $\begin{array}{l}\text { Interest in using it to } \\
\text { control fruit flies in } \\
\text { organic farms in } \\
\text { Northeast of Brazil }\end{array}$ & $\begin{array}{l}\text { Vargas et al. } \\
\text { (1993, 2007), } \\
\text { Waterhouse (1993), } \\
\text { Holler et al. (1996), } \\
\text { Ovruski et al. } \\
\text { (2000), Wang et al. } \\
\text { (2004), Carmichael } \\
\text { et al. (2005), Rousse } \\
\text { et al. (2005) }\end{array}$ \\
\hline $\begin{array}{l}\text { Harmonia } \\
\text { axyridis } \\
\text { (Pallas, 1773) } \\
\text { (Coleoptera: } \\
\text { Coccinellidae) }\end{array}$ & $\begin{array}{l}\text { Predatory lady beetle } \\
\text { introduced in many } \\
\text { countries to control } \\
\text { aphids }\end{array}$ & Northeast Asia & $\begin{array}{l}38 \text { countries in } \\
\text { North and } \\
\text { South } \\
\text { Americas, } \\
\text { Africa and } \\
\text { Europe }\end{array}$ & $\begin{array}{l}\text { Vast record of } \\
\text { invasions and } \\
\text { establishment, as } \\
\text { well as associated } \\
\text { adverse effects }\end{array}$ & e.g., Roy et al. (2016) \\
\hline $\begin{array}{l}\text { Macrolophus } \\
\text { pygmaeus } \\
\text { (Rambur, 1839) } \\
\text { (Hemiptera: } \\
\text { Miridae) }\end{array}$ & $\begin{array}{l}\text { Predatory mirid sold } \\
\text { commercially in } \\
\text { Europe for } \\
\text { augmentative } \\
\text { biological control in } \\
\text { greenhouses }\end{array}$ & $\begin{array}{l}\text { Mediterranean } \\
\text { basin }\end{array}$ & $\begin{array}{l}\text { Augmentative } \\
\text { biological } \\
\text { control agent } \\
\text { in Europe }\end{array}$ & $\begin{array}{l}\text { Permit declined in } \\
\text { New Zealand in } 2014 \\
\text { for augmentative } \\
\text { BCA for greenhouse } \\
\text { tomatoes due to } \\
\text { likely to establish } \\
\text { outside of the } \\
\text { greenhouses }\end{array}$ & $\begin{array}{l}\text { Castañé et al. (2011), } \\
\text { EPA }(2013,2014)\end{array}$ \\
\hline
\end{tabular}

in the case data acquisition (last tier) is required to quantify risks on non-target species.

\section{Tier 1: Scoping Assessment}

The Scoping Assessment (Fig. 2) relies on expert consultation to use existing scientific information on a case-by-case basis to evaluate the following six sections. It focuses on determining the potential benefits and adverse environmental effects of a GABCA.
Intended use and likely benefits

The intended use of the exotic GABCA, including the intended target pest(s) and the crop or commodity attacked must be provided, as well as time of the year (augmentative BC) and geographic area of the intended release. The potential benefits from the exotic GABCA release must be described, including the likely level of control of the target pest(s), replacement or reduction of existing plant protection actions (e.g., pesticides) and protection of biodiversity. A literature review of the host/prey species and habitat use of the exotic GABCA should also be conducted to enable understanding and evaluation of the general risk-benefit tradeoff, which significantly affects the acceptance of the exotic GABCA risks. 


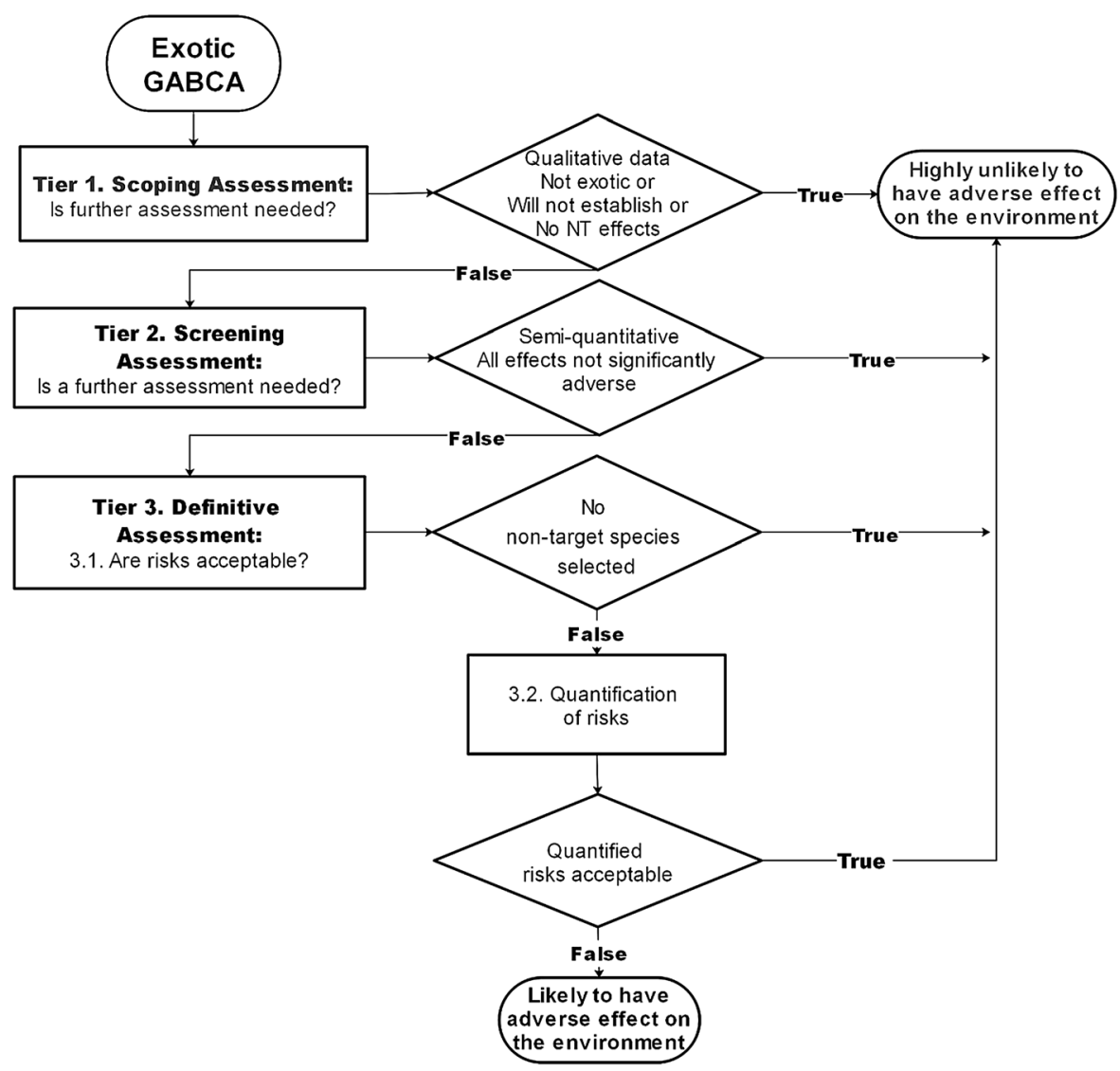

Fig. 1 Overall proposed tiered environmental risk assessment for exotic GABCAs. The flowchart symbols indicate: oval a beginning or end, rectangle a step of the process, diamond a decision, arrow direction of flow

Species identification

Confirmation of the identity of the exotic BCA must be certified by a taxonomic specialist to reduce or eliminate the possibility of sibling or cryptic species (Le Hesran et al. 2019). The specimens must be deposited in a curated permanent collection and the taxonomist must provide a certificate of identification with the method used to identify the species. In the case of a taxon without a single species name (species complex, subspecies, biotypes), distinction from other entities of the same rank must be provided.

Level of polyphagy

As there is a diet gradient from specialist to generalist BCAs, it is crucial to assess the level of polyphagy. General classifications of polyphagy are mostly based on the number of host/prey (e.g., groups of $0,1-3$,
4-10, 11-30 and $>30$ species) or taxonomic relatedness of the host/prey (e.g., same genus) (e.g., van Lenteren et al. 2003). These are easy to implement unambiguously but are not directly related to risk. An approach based on the functional relationship between the exotic GABCA and its hosts/prey is more closely related to risks and may be critical for risk assessment but requires a level of detail that is typically unavailable. One example is the McMurtry et al. (2013) classification of phytoseiid predatory mites based on the functional similarity of the prey species. Functionally specialized phytoseiids feed only on functionally similar species, such as only Tetranychus mites, tydeoid mites, or tetranychiid web-nest producing mites. None of these functionally specialized predators would be considered specialists by the general classifications mentioned above. However, because the prey species all have functionally similar ecologies, the assessment of risks will be similar for all 


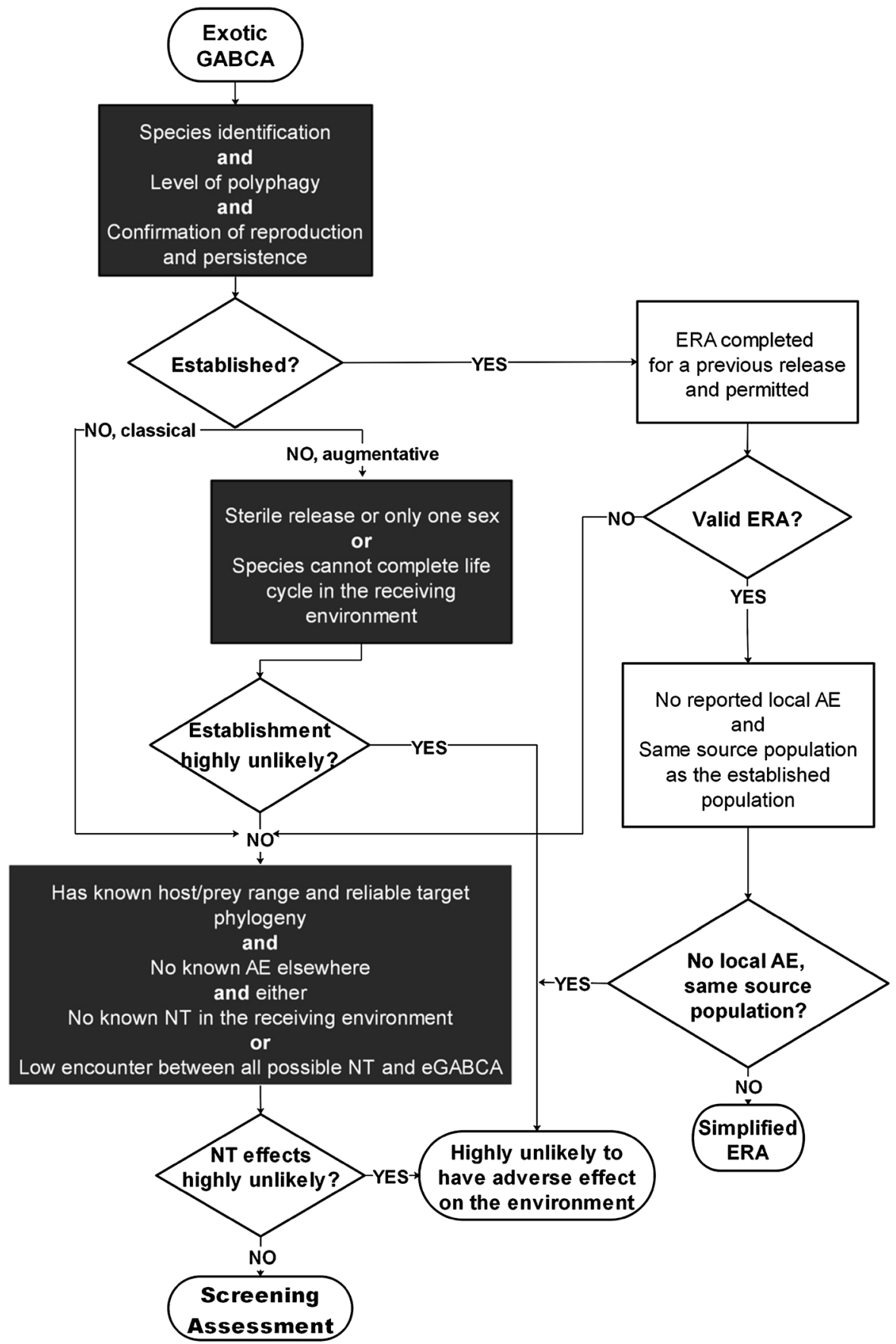

Fig. 2 Tier 1: Scoping Assessment. The flowchart symbols indicate: oval a beginning or end, rectangle a step of the process, diamond a decision, arrow direction of flow, black background indicates an expert consultation process. $A E$ adverse effect; $N T$ non-target species

the species, which will greatly simplify the assessment. In a case where there is insufficient biological knowledge about the level of polyphagy of the exotic
GABCA to complete the Scoping Assessment, the ERA continues to the Screening Assessment where such knowledge must be provided. 
Status of establishment of exotic GABCA

The importance of the verification of the establishment (or lack thereof) of an exotic GABCA resides in the fact that, once established, a permit for introduction may not be necessary and, in many jurisdictions, a permit for commercial release will not require an ERA. Also, verification of the geographic distribution of establishment is recommended, as the distribution could significantly affect permit approval for movement and release. To prove that the exotic GABCA is already established, evidence of successful reproduction and persistence must be demonstrated through records of presence (e.g., labeled specimens in collections, records in publications, biopesticide registration certificates, ecological samples, internetbased recording schemes) of adults and, where possible, immatures. The minimum time frame for records of presence to demonstrate establishment of the exotic GABCA will be defined by a specialist, designated by the regulatory agency, based on the species life cycle and biology, and it should be greater than the time needed to complete at least three generations and one annual cycle. If establishment is in doubt or cannot be demonstrated, the ERA continues to "Potential establishment of an augmentative exotic GABCA" section of the Scoping Assessment.

If the exotic GABCA is established, the ERA continues as follows:

A. Reintroductions of an established exotic species are considered to have low environmental risk and need no further risk assessment if all of the following conditions are met: (1) previous release was authorized by a competent authority based on a valid ERA (i.e., no significant changes in biological or regulatory circumstances); (2) adverse effects were not observed during testing or after release where the exotic GABCA is established on known at risk non-target species (usually identified using criteria such as phylogenetic, ecological, biological and/or socio-economic criteria; Sands and van Driesche 2004; Kuhlmann et al. 2006; Barratt et al. 2016); (3) the source of the exotic population to be released is the same as the established population.

B. Reintroductions that do not have a valid ERA (condition $A_{1}$ ) should proceed to "Potential establishment of an augmentative exotic GABCA" section of the Scoping Assessment.

C. Reintroductions that do not meet condition $\mathrm{A}_{2}$ or $\mathrm{A}_{3}$ should continue with a simplified ERA (see Supplementary Material), which is focused on evaluating if these conditions can be met or if a full ERA is necessary.

Potential establishment of an augmentative exotic GABCA

For an augmentative exotic GABCA, either of the following can be used to demonstrate that it is highly unlikely to establish, including any environment besides open field:

A. The release comprises only sterile individuals or only one sex of a non-parthenogenetic species.

B. The exotic GABCA cannot complete its life cycle outside a protected environment in the geographical region where it is intended for release due to any one of the following: (1) absence of suitable host/prey; (2) asynchrony of the predicted life cycle with suitable hosts or their host plants or prey; (3) abiotic or climate conditions (including conditions anticipated for the future, e.g. possibly next ten years) that prevent survival at some time during an annual cycle.

If it cannot be shown that the exotic GABCA is highly unlikely to establish, the ERA continues to "Qualitative non-target species assessment" section of the Scoping Assessment. Otherwise the exotic GABCA can be considered highly unlikely to establish and therefore highly unlikely to have an adverse effect on the environment. In this case, there is no need for further ERA.

Qualitative non-target species assessment

For augmentative releases of exotic GABCA that may establish, including outside a protected environment, or classical releases of exotic GABCA, the following must be provided: (1) a list of the known host/prey range and species with which the exotic GABCA directly interacts wherever it occurs (native range and any place it has established); (2) a summary of the status of the phylogenetic relationships for the known host/prey species and species with which it directly 
interacts. Then, the following two requirements must be met to determine that an adverse non-target effect is highly unlikely:

A. No record of adverse effect on any non-target species elsewhere in the world. This assumes that if there are no direct effects on any non-target species, then there are no indirect effects of the exotic GABCA, because all indirect effects must involve at least one direct effect (Messing et al. 2006). In addition, the record(s) of adverse effects must be on the population of the non-target species, and not merely records of parasitism/ predation.

B. Lack of an expected adverse effect in the geographic region where it is intended to be released due to any of the following:

(1) Absence of non-target species in the intended release region based on the known host/prey in the natural range or other areas where it was previously introduced, for all the 19 categories of effects in Table 2. These categories expand on a shorter list in Snyder and Evans (2006).

(2) Lack of encounter (spatial or temporal overlap) with the potential non-target species in the intended release region.

(3) Existence of a biological constraint limiting the interaction of potential non-target species with the exotic GABCA (e.g., unrecognized chemical/biological cues, ovipositor not long enough to reach nontarget species; etc.).

If it cannot be determined that the exotic GABCA is highly unlikely to have an adverse effect, the ERA continues to the Screening Assessment. Otherwise, the exotic GABCA is considered highly unlikely to have an adverse effect on the environment and, hence, requires no further ERA.

\section{Tier 2: Screening Assessment}

In this tier (Fig. 3), risk is estimated and characterized using worst case assumptions for the Likelihood of establishment $(L E)$ and potential Adverse effect $(A E)$. For classical releases, $L E$ is set to 1 (certain to establish), because the intent of the release is to establish the exotic GABCA. For augmentative releases, the exact probability of establishment is greater than 0 , so as a worst-case assumption, $L E$ is also set to 1 . The potential $A E$ is quantified for each of the 19 categories of effects (Table 2), using readily available data and conservative assumptions by experts.

\section{Adverse effect (AE)}

In the 19 categories of effects (Table 2) each category is designated with the subscript $i$, with $i=1, \ldots, 19$. These categories of effects were designed to allow independent discrimination of interdependent or correlated factors so that their individual importance can be clearly judged. The $A E$ associated with each category of effect $i$ is estimated by an expert consultation panel through the 'adverse effect' form ( $A E$ form, Table 2), which follows elicitation methods described by Kynn (2008) and Vanderhoeven et al. (2017). In the $A E$ form, each of the categories of effect is scored according to Likelihood of effect $\left(L E f_{i}\right)$ and Magnitude of effect $\left(M E f_{i}\right)$ on a non-target species in category $i . A E_{i}$ is then estimated by:

$A E_{i}=L E f_{i} \times M E f_{i}$

We proposed ordinal scales (Table 2) to score $L E f_{i}$ and $M E f_{i}$. The odd number of choices anchored to specific values is to enhance score accuracy (O'Hagan 2005; Morgan 2014). Each category of effect is scored with the highest, lowest and median scores (in that order). Scoring the extremes first eliminates arbitrary anchoring bias for the median score. Anchoring bias is a cognitive bias that occurs when an individual favors their initial considerations over more comprehensive sources of information. If the median is scored first, arbitrary information, possibly unique to each expert will bias the estimate. Instead, the median is anchored to both extremes, which will force the expert to consider the median to be a score between these values, thereby eliminating arbitrary anchoring bias. The scoring of extremes also allows consideration of different conditions/scenarios that might result in different $L E f_{i}$ or $M E f_{i}$, and provides the regulator an indication of the associated uncertainty (Morgan 2014). A brief justification for the scores must be provided to clarify to the regulator the technical knowledge and experience used, and the level of subjectivity (O'Hagan 2005). This is particularly 
D. P. Paula et al.

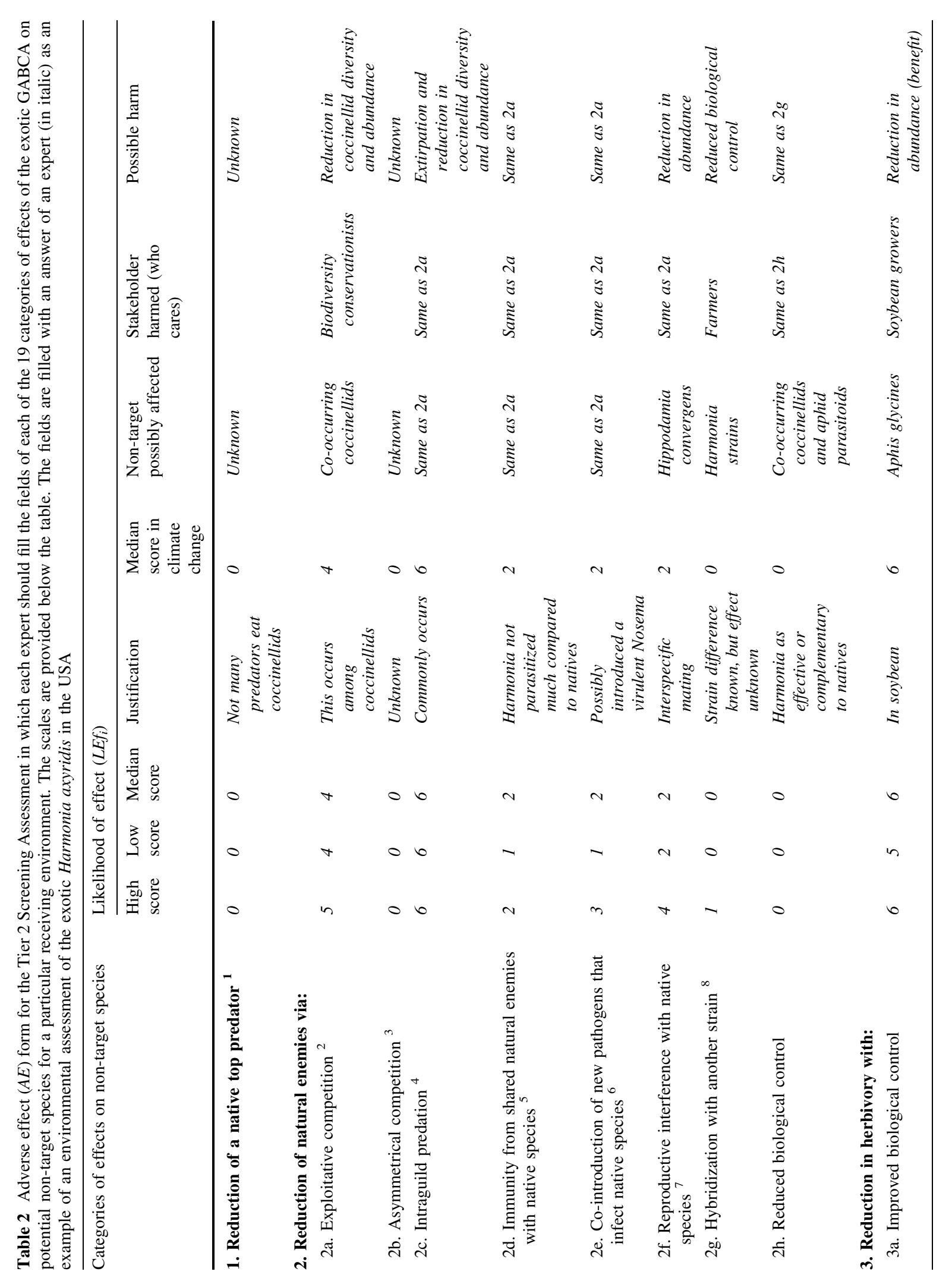




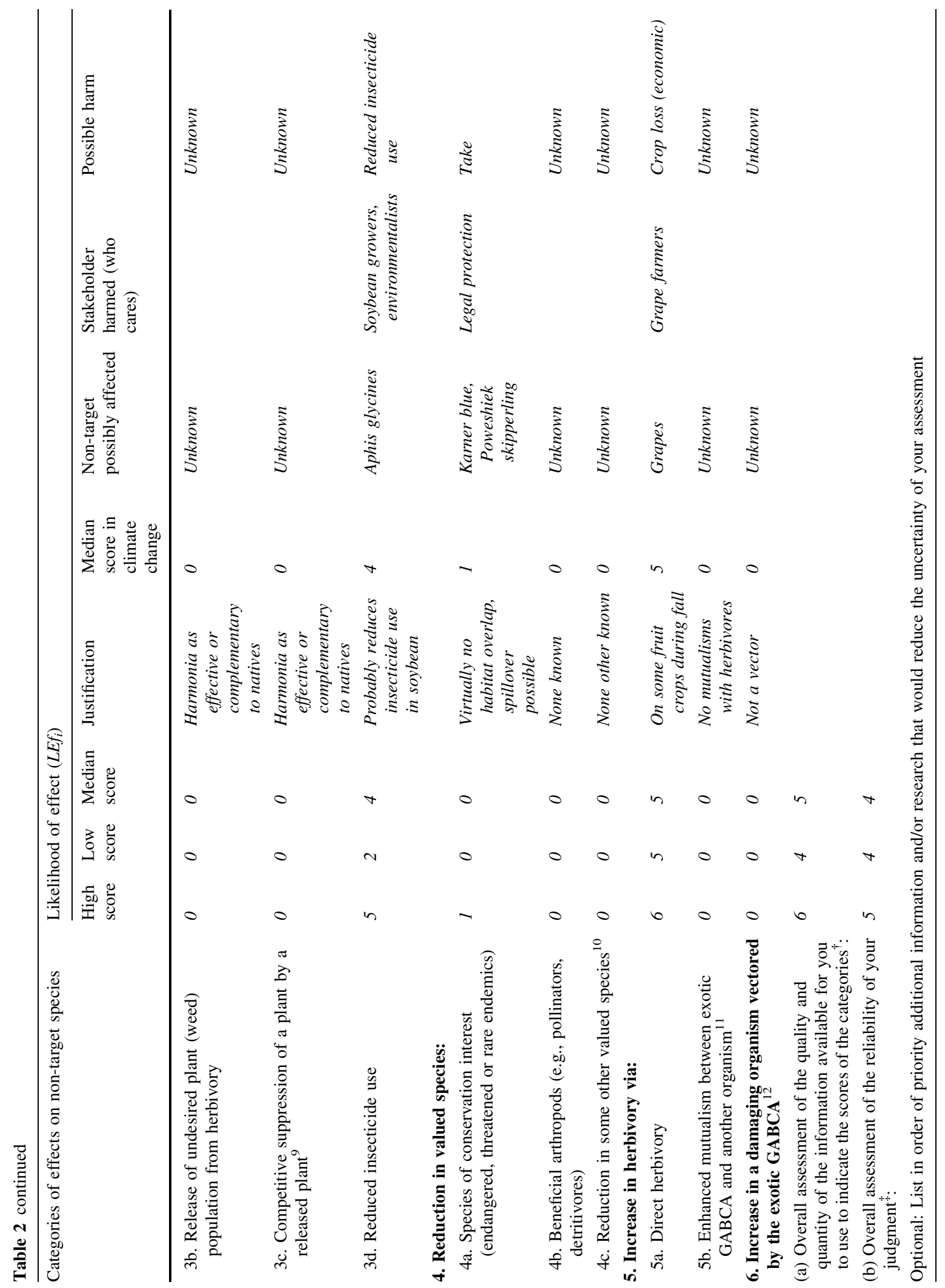




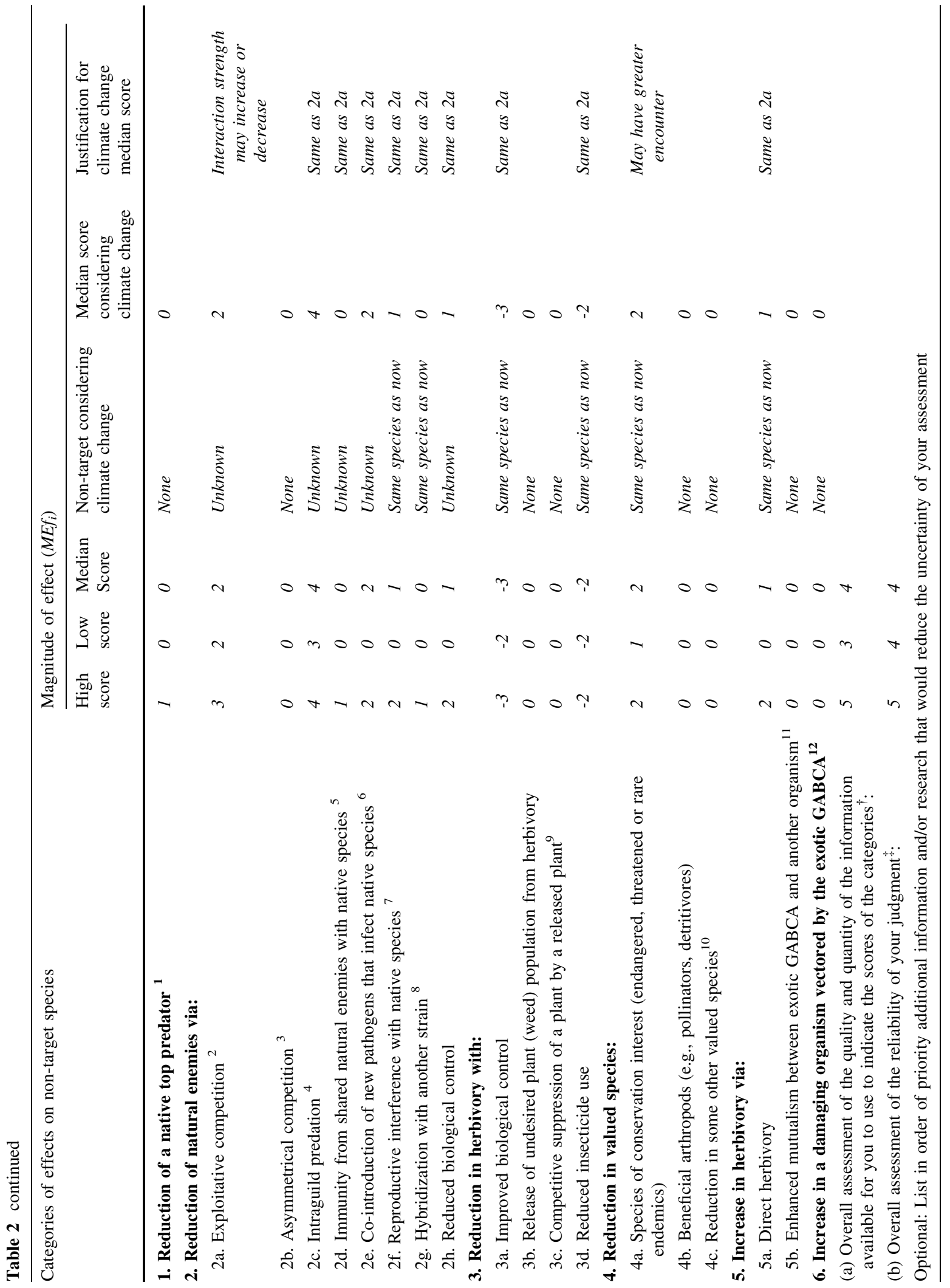




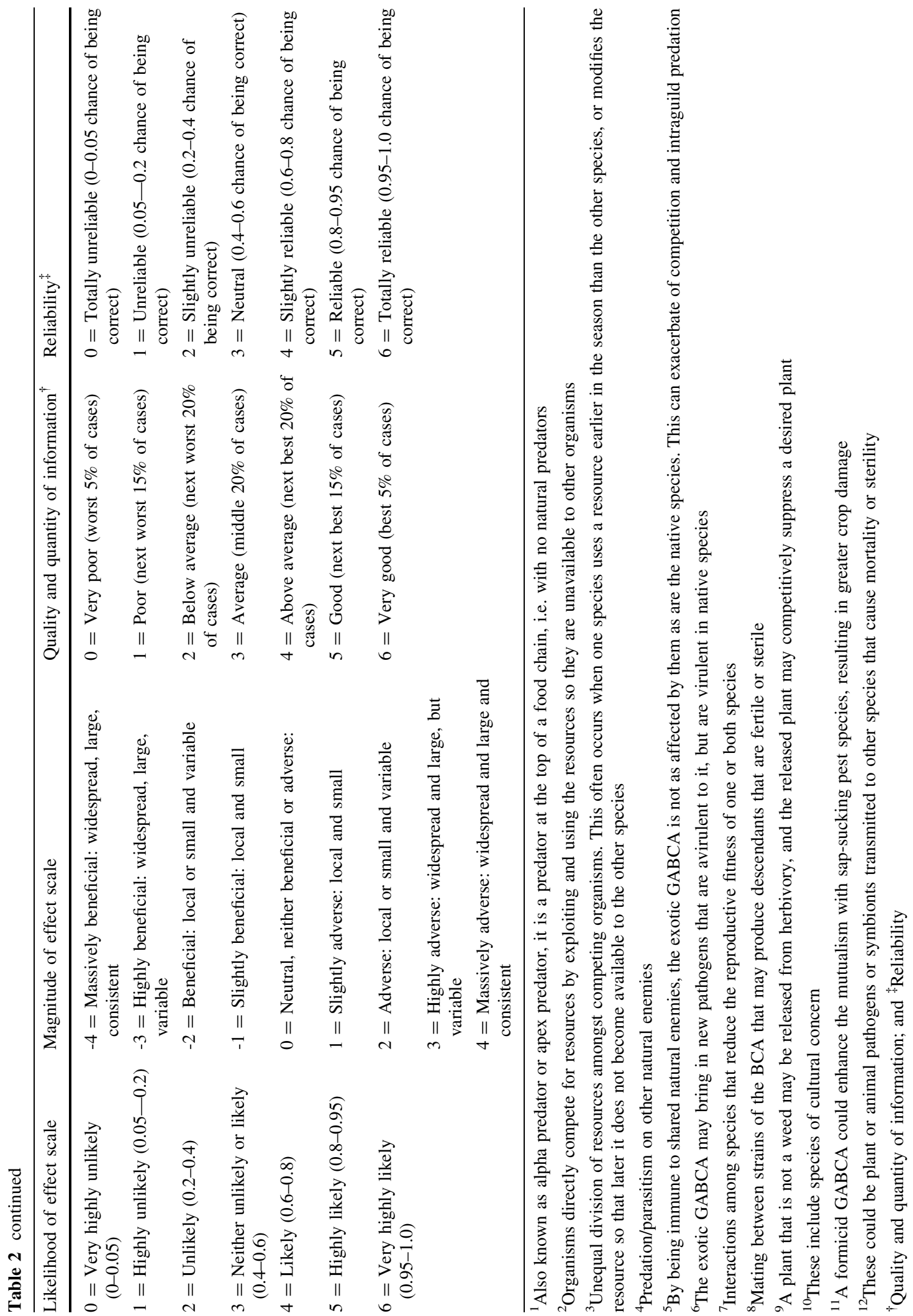




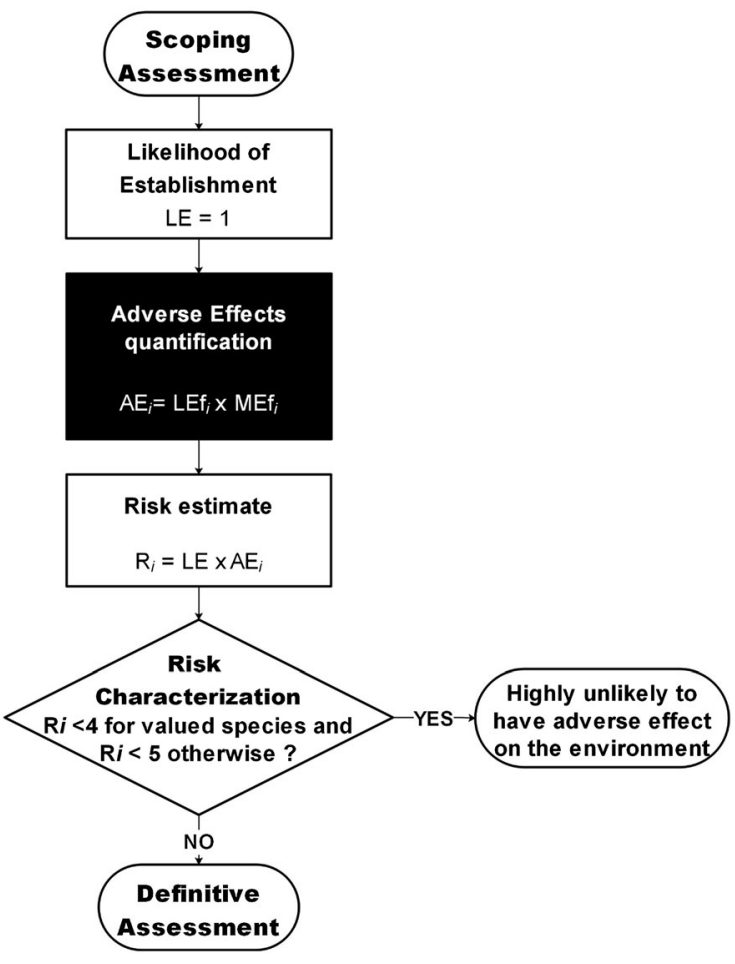

Fig. 3 Tier 2: screening assessment. The flowchart symbols indicate: oval a beginning or end, rectangle a step of the process, diamond a decision, arrow direction of flow. Black background indicates an expert consultation process. $L E$ likelihood of establishment, $A E$ adverse effect, $i$ a category of effect, $L E f$ likelihood of effect, $M E f=$ magnitude of effect, $R=$ risk

important when the same category of effect receives highly variable scores among experts, because it provides a way for the regulator to moderate or weight scores of different experts. The possible effects of plausible climate change scenarios are also scored (only as a change in the median score) to communicate the relative stability (or dependence) of the score on present conditions or circumstances.

The scientific name(s) of some non-target species possibly affected, the stakeholders concerned, and a description of the possible harm must also be provided. The non-target species list does not need to be comprehensive, but is needed to ensure that the estimated values have specificity and are not based on generalities. The identification of stakeholders and possible harm is essential to ensure that the effect is actually adverse and to ensure that the estimate of the magnitude of the effect is based on more than an impact on a non-target. For an effect to be considered adverse, it must harm some group of stakeholders, and the magnitude of the effect should be based on the size of the harm, not merely on the effect on the non-target species.

Finally, an overall assessment of the quality and quantity of the information available for scoring and reliability of the judgment (second order uncertainty) is also provided, which allows the regulator ways to evaluate if the answers were based more on general experience/knowledge or on actual data for the exotic BCA (Morgan 2014). This empowers the regulator to weigh the entire response of an expert when experts give highly different scores, which may happen. As an option, the expert may list in order of priority, additional information and/or research that would reduce the uncertainty of the assessment. This provides an opportunity for the regulator to become aware of (or sensitized to) research areas that need to be encouraged (Morgan 2014).

The $A E$ form completed by the experts can be combined by the regulator into a single score using fuzzy systems. A fuzzy system is proposed because it accounts for and quantitatively preserves uncertainty related to lack of knowledge. This is more realistic than standard logic for evaluating the safety of an environmental stressor when there are knowledge gaps. Fuzzy systems are based on the concept of membership. For example, suppose for some likelihood of an effect, $L E f_{i}$, that minimum score is 0.1 , so it cannot be less than 0.1 (membership of 0 ) and could possibly be greater than 0.5 (membership of 1), but we have no information to know if it could possibly be between 0.1 and 0.5 . Under standard logic, we would have to assume that it was possible or not ( 0 or 1 ), between 0.1 and 0.5 , but under fuzzy systems, we can specify a membership between 0 and 1 to reflect the knowledge gap. Depending on the assumption, standard logic would over or underestimate the true value because it ignores the knowledge gap.

To apply a fuzzy system to the scores in the $A E$ form, the high, low and median scores for each $L E f_{i}$ and $M E f_{i}$ are converted into fuzzy sets (Pedrycz and Gomide 2007). The fuzzy sets for $L E f_{i}$ and $M E f_{i}$ for each responding expert are multiplied together (Rahman 2016) to produce a fuzzy set for adverse effect $i\left(A E_{i}\right)$ for each expert. The $A E_{i}$ fuzzy sets of all experts are averaged into an aggregated fuzzy set and defuzzified by the centroid method to produce an estimated value of $A E_{i}$ (Table 3 ). The centroid is the weighted mean $A E_{i}$, weighted by the membership in 
Table 3 Adverse effect $(A E)$ calculated for each category of effect obtained from 13 experts answers to the $A E$ form for the Harmonia axyridis example (Table 2) and, consequently, the associated risk score using the upper $0.5 \lambda$-cut parameter. To

\begin{tabular}{llll}
\hline Potential effects and & \multicolumn{2}{l}{ Adverse effect } & \\
\cline { 2 - 3 } $\begin{array}{l}\text { categories of effects on non- } \\
\text { target species }\end{array}$ & Centroid & Upper & Centroid \\
& & $0.5 \lambda$ - & for \\
& & cut & climate \\
& & & change
\end{tabular}

characterize the acceptability of the risk, six risk threshold options were tested. Categories of effects marked with an X have risk scored above the proposed threshold and, therefore, would need to be evaluated in the Definitive Assessment

\begin{tabular}{|c|c|c|c|c|c|c|c|c|c|c|}
\hline $\begin{array}{l}\text { 1. Reduction of a native top } \\
\text { predator }\end{array}$ & 0 & 0 & 0 & 0 & & & & & & \\
\hline \multicolumn{11}{|l|}{$\begin{array}{l}\text { 2. Reduction of native natural } \\
\text { enemies via: }\end{array}$} \\
\hline 2a. Exploitative competition & 9.7 & 11.7 & 9.7 & 11.7 & $\mathrm{X}$ & $\mathrm{X}$ & $\mathrm{X}$ & $\mathrm{X}$ & $\mathrm{X}$ & $\mathrm{X}$ \\
\hline $\begin{array}{l}\text { 2b. Asymmetrical } \\
\text { competition }\end{array}$ & 0 & 0 & 0 & 0 & & & & & & \\
\hline 2c. Intraguild predation & 22.2 & 24 & 22.2 & 24 & $\mathrm{X}$ & $\mathrm{X}$ & $\mathrm{X}$ & $\mathrm{X}$ & $\mathrm{X}$ & $\mathrm{X}$ \\
\hline $\begin{array}{l}\text { 2d. Immunity from shared } \\
\text { natural enemies with } \\
\text { native species }\end{array}$ & 0.5 & 1.1 & 0.5 & 1.1 & & & & & & \\
\hline $\begin{array}{l}\text { 2e. Co-introduction of new } \\
\text { pathogens that infect } \\
\text { native species }\end{array}$ & 2.5 & 4.1 & 2.5 & 4.1 & & & $\mathrm{X}$ & & & \\
\hline $\begin{array}{l}\text { 2f. Reproductive } \\
\text { interference with native } \\
\text { species }\end{array}$ & 2.9 & 5.2 & 2.9 & 5.2 & & $\mathrm{X}$ & $\mathrm{X}$ & $\mathrm{X}$ & $\mathrm{X}$ & $\mathrm{X}$ \\
\hline $\begin{array}{l}\text { 2g. Hybridization with } \\
\text { another strain }\end{array}$ & 0.2 & 0.5 & 0.2 & 0.5 & & & & & & \\
\hline $\begin{array}{l}\text { 2h. Reduced biological } \\
\text { control }\end{array}$ & 0 & 0 & 0 & 0 & & & & & & \\
\hline \multicolumn{11}{|l|}{$\begin{array}{l}\text { 3. Reduction in herbivory } \\
\text { with: }\end{array}$} \\
\hline $\begin{array}{l}\text { 3a. Improved biological } \\
\text { control }\end{array}$ & -15.5 & -18.0 & -15.5 & -18.0 & & & & & & \\
\hline $\begin{array}{l}\text { 3b. Release of undesired } \\
\text { plant (weed) population } \\
\text { from herbivory }\end{array}$ & 0 & 0 & 0 & 0 & & & & & & \\
\hline $\begin{array}{l}\text { 3c. Competitive suppression } \\
\text { of a plant by a released } \\
\text { plant }\end{array}$ & 0 & 0 & 0 & 0 & & & & & & \\
\hline 3d. Reduced insecticide use & -7.4 & -9.1 & -7.4 & -9.1 & & & & & & \\
\hline \multicolumn{11}{|l|}{$\begin{array}{l}\text { 4. Reduction in valued } \\
\text { species: }\end{array}$} \\
\hline $\begin{array}{l}\text { 4a. Species of conservation } \\
\text { interest (endangered, } \\
\text { threatened or rare } \\
\text { endemics) }\end{array}$ & 0.5 & 1.1 & 1.4 & 1.1 & & & & & & \\
\hline $\begin{array}{l}\text { 4b. Beneficial arthropods } \\
\text { (e.g., pollinators, } \\
\text { detritivores) }\end{array}$ & 0 & 0 & 0 & 0 & & & & & & \\
\hline $\begin{array}{l}\text { 4c. Endemic species or } \\
\text { species of cultural value }\end{array}$ & 0 & 0 & 0 & 0 & & & & & & \\
\hline
\end{tabular}


Table 3 continued

\begin{tabular}{|c|c|c|c|c|c|c|c|c|c|c|}
\hline \multirow{2}{*}{$\begin{array}{l}\text { Potential effects and } \\
\text { categories of effects on non- } \\
\text { target species }\end{array}$} & \multicolumn{3}{|c|}{ Adverse effect } & \multirow{2}{*}{$\begin{array}{l}\text { Risk } \\
\text { (R) }\end{array}$} & \multicolumn{6}{|c|}{ Threshold options } \\
\hline & Centroid & $\begin{array}{l}\text { Upper } \\
0.5 \lambda- \\
\text { cut }\end{array}$ & $\begin{array}{l}\text { Centroid } \\
\text { for } \\
\text { climate } \\
\text { change }\end{array}$ & & $\mathrm{R}>6$ & $\mathrm{R} \geq 5$ & $\mathrm{R} \geq 4$ & $\mathrm{R} \geq 3^{*}$ & $\mathrm{R} \geq 4 * *$ & $\mathrm{R} \geq 4^{* * *}$ \\
\hline \multicolumn{11}{|l|}{ 5. Increase in herbivory via } \\
\hline 5a. Direct herbivory & 5.5 & 8.7 & 5.5 & 8.7 & $\mathrm{X}$ & $\mathrm{X}$ & $X$ & $X$ & $X$ & $X$ \\
\hline $\begin{array}{l}\text { 5b. Enhanced mutualism } \\
\text { between exotic GABCA } \\
\text { and another organism }\end{array}$ & 0 & 0 & 0 & 0 & & & & & & \\
\hline $\begin{array}{l}\text { 6. Increase in a damaging } \\
\text { organism vectored by the } \\
\text { exotic GABCA }\end{array}$ & 0 & 0 & 0 & 0 & & & & & & \\
\hline $\begin{array}{l}\text { Categories with risk (R) above } \\
\text { the threshold }\end{array}$ & & & & & 3 & 4 & 5 & 4 & 4 & 4 \\
\hline
\end{tabular}

the fuzzy set. The variation among expert scores is measured by a $\lambda$-cut of the aggregated $A E_{i}$ fuzzy set with membership equal to 0.5 (this is like a SD) (Table 3). As the Screening Assessment uses conservative assumptions, the upper value of the $\lambda$-cut is used as an estimate of $A E_{i}$. The fuzzy set calculations should be automatically provided by embedded formulas in the compiled $A E$ form so that regulators or experts would not be required to calculate them.

\section{Risk characterization}

Having set the $L E=1$, and estimated the $A E_{i}$ (Table 3) using conservative assumptions, the risk $\left(\mathrm{R}_{i}\right)$ associated with each category of effect $i$ can be estimated by:

$\mathrm{R}_{i}=L E \times A E_{i}=A E_{i}$,

which is given above as the upper $0.5 \lambda$-cut of the $A E_{\mathrm{i}}$ average fuzzy set. In addition to calculating a risk, risk characterization involves determining which risks are important enough to merit definitive assessment (Tier 3).

To determine thresholds to characterize the risk, we first tested the acceptability of various risk thresholds by allowing experts to consider the results of the Screening Assessment for exotic GABCAs with which they were familiar (forum 5 in Supplementary
Material). This resulted in six proposed thresholds (Table 3), which were subsequently evaluated by 13 experts using the well-known case of the predatory Asian ladybeetle Harmonia axyridis (Pallas) (Coleoptera: Coccinellidae) established in the USA. The thresholds $\mathrm{R} \geq 5, \mathrm{R} \geq 3^{*}, \mathrm{R} \geq 4 * *$ and $\mathrm{R} \geq 4 * * *$ indicated the same categories for additional assessment and were intermediate between the $\mathrm{R}>6$ and $\mathrm{R} \geq 4$ (Table 3). Experts considered threshold $\mathrm{R}>6$ to be too high and threshold $\mathrm{R}>4$ to be too low. The thresholds $\mathrm{R} \geq 3^{*}, \mathrm{R} \geq 4^{* *}$ and $\mathrm{R} \geq 4^{* * *}$ were considered unnecessarily complex. A category of effect with $\mathrm{R}<5$ means that in the worst case, the effect would be either likely and slightly adverse (local and small), unlikely and adverse (local or small and variable), or highly unlikely and potentially massively adverse (widespread, large and consistent). Hence, the threshold $\mathrm{R} \geq 5$ was selected as the risk threshold for potential adverse effects to need a definitive assessment. However, experts believed that the threshold for valued species should be lower because these species need additional protection. A category of effect with $\mathrm{R}<4$ indicates that in the worst case, the effect would be either unlikely and slightly adverse (local and small) or highly unlikely and adverse (local or small and variable). Experts agreed that for valued species 


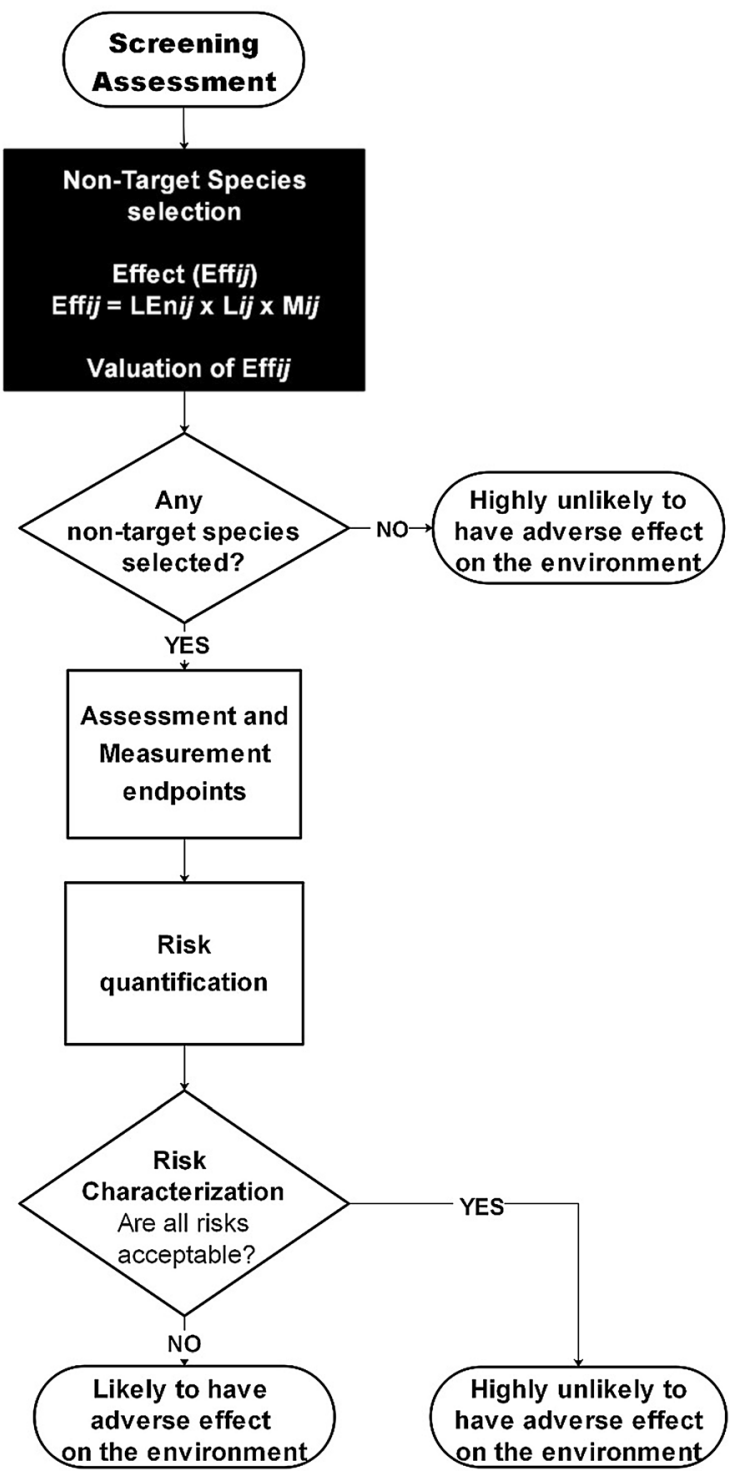

Fig. 4 Tier 3: Definitive Assessment. The flowchart symbols indicate: oval a beginning or end, rectangle a step of the process, diamond a decision, arrow direction of flow. Black background indicates an expert consultation process. $i=$ category of adverse effect, $j=$ a non-target species; Eff $i j=$ overall shortterm effect of an exotic GABCA on a non-target species $j$; LEn $i j=$ Likelihood of encounter between the exotic GABCA with the non-target species $j$; Lij $=$ likelihood of an effect on non-target species $j$ after encounter; Mij= magnitude of an effect on non-target species $\mathrm{j}$ after encounter

the threshold should be $R \geq 4$ needing definitive assessment.

Having established the risk thresholds of $R \geq 4$ for endangered, threatened, or rare endemic species, and $\mathrm{R} \geq 5$ otherwise for effects that require further analysis in the Definitive Assessment, the $H$. axyridis example in the USA (Table 3) indicates that there were four categories of effects with risks above the threshold: exploitative competition $(\mathrm{R}=11.7)$, intraguild predation $(\mathrm{R}=24)$, reproductive interference with native species $(\mathrm{R}=5.2)$ and direct herbivory ( $\mathrm{R}=8.7$, on grapes). Subsequently, if a petition was continued, the risks associated with those four categories of effects would need to be evaluated in a definitive assessment. In the case that all of the potential categories of effect for the exotic GABCA have risks $<4$ for valued species and $<5$ otherwise, the exotic GABCA can be considered highly unlikely to have a significant adverse effect on the environment, and there is no need for further ERA. For example, for the oligophagous parasitic wasp Fopius arisanus (Sonan, 1932), (Hymenoptera: Braconidae) in Brazil, there was no category of effect with risk above the threshold. Therefore, F. arisanus would be considered highly unlikely to have a significant adverse effect in Brazil and the ERA would be concluded.

Benefit scores (negative risks) for both $F$. arisanus and $H$. axyridis were high for improved biological control $(\mathrm{R}=-10.7$ and -18.0$)$ and reduced insecticide use $(\mathrm{R}=-8.2$ and -9.1$)$, respectively. Therefore, for $F$. arisanus, the potential benefits may outweigh the potential risks of a release. For $H$. axyridis, the four potential risks identified were not outweighed by the two potential benefits. These case studies exemplify that risk characterization in this Screening Assessment takes into consideration three kinds of effects: adverse effects (risk scores above the thresholds), benefits (risk scores below zero) and neutral (risk scores between zero and the thresholds, i.e. insignificant $A E$ ), and provides the regulator the opportunity to compare and weigh them.

\section{Tier 3: Definitive Assessment}

The Definitive Assessment (Fig. 4) provides a quantification of the risks of an exotic GABCA for the category(ies) of effect(s) that scored $\mathrm{R} \geq 4$ for endangered, threatened, or rare endemic species, and $\mathrm{R} \geq 5$ otherwise, in the Screening Assessment. It proceeds by: 
A. Identifying non-target species with potentially significant risk(s). If a species list is not already available, research in the receiving environment must be conducted to create the list. The applicant is responsible for providing a reliable list of species to be confirmed by the regulatory body.

B. Specifying the mechanistic pathway(s) of adverse effect(s). This is achieved using interaction networks involving the exotic GABCA and the identified non-target species.

C. Identifying assessment and measurement endpoint(s). An assessment endpoint is an attribute (e.g., abundance, distribution, etc.) of the nontarget species that is assessed via a measurement endpoint, which is a quantifiable indicator of the assessment endpoint.

D. Generating estimates of risk component(s). This includes establishment of the exotic GABCA, encounter between the exotic GABCA and the non-target species, and effects on that species or ecosystem services.

E. Characterizing risk. This involves combining the components and then interpreting if it is acceptable or not.

\section{Non-target species identification}

In previous non-target species selection methods (e.g., Kuhlmann et al. 2006; Todd et al. 2015), the potential non-target species are listed at the beginning of the ERA, resulting in a large number of non-target species, which are then filtered in subsequent steps. Unlike those methods, the initial list of potential nontarget species to be examined in the Definitive Assessment is based on the results of the risk characterization from the Screening Assessment for each category of effect in which the risk scored above the threshold, i.e. only potentially significant adverse effects, will be considered. For example, for $H$. axyridis in the USA (Table 3), experts would look for non-target species in four categories of effects with risk above the threshold, and select representative test species for each category using the 'non-target species form' (NT form, Table 4). For the case of exploitative competition, the potential non-target species would be other natural enemies with which $H$. axyridis is likely to compete for similar prey. This category and the reproductive interference category emphasize the fact that relevant non-target species can be outside of the host/prey range and would not require host/prey range test(s).

For some categories of effects, host/prey range tests may be needed to determine the potential non-target species, such as for intraguild predation, direct herbivory and species of conservation concern. The applicant, the regulatory agency or a third party could be responsible for collecting the necessary data, but policies could be considered so that the process is transparent, that small companies and BCAs for local and small market crops are not excluded and that potential conflicts of interest are appropriately managed. The non-target species identification process presented here provides a rough quantitative risk estimate, building on Kuhlmann et al. (2006) and PRONTI (Barratt et al. 2016).

The objective of the NT form is to link characteristics of the non-target species with elements of risk to identify species that may have greater short-term effects and might need additional testing to determine long-term effects. This is achieved by making realistic estimates of components that are used to estimate the short-term effect(s) of the exotic GABCA on each potential non-target species using expert consultation and scientific data. The short-term effect of the exotic GABCA on a non-target species is the proportion of non-target individuals in a generation that is expected to be killed/reduced/affected by an established population of the exotic GABCA (e.g., Hopper 2001). Long-term effects on a population require careful analysis of how such short-term effects interact with the mechanisms regulating the non-target population, to determine if the short-term effects actually affect the long-term equilibrium population size. Thus, a short-term effect is highly unlikely to underestimate the long-term effect on the non-target population. These short-term effects are then extended to determine if any of the non-target species require an evaluation of long-term population and indirect ecosystem effects. As indirect ecosystem effects will generally require a long-term change in the population of the non-target, using short-term effects for these indirect ecosystem effects is also unlikely to underestimate them as well. This has the advantage of delaying or avoiding the need to evaluate long-term population and indirect ecosystem effects, which can be expensive and time-consuming, to the last steps of the Definitive Assessment. Finally, the estimated 
Table 4 Non-target (NT) species form to evaluate short term effects of an exotic GABCA on a non-target species $j$ in category of effect $i$ (Effij) for the exotic Harmonia axyridis in the USA, considering the category of effect " $2 \mathrm{c}$. Intraguild predation" with $\mathrm{R}=24$ from the Screening Assessment. Each expert should provide estimates (between 0 and 1) for each parameter (answers are exemplified in italics). Numbers in bold are automatically calculated. If estimates cannot be provided, expert should note with an explanation. Alternatively, expert may provide the highest score possible and note this in comments. More columns should be added for additional species. Cma = Coleomegilla maculata Cmu = Cycloneda munda

\begin{tabular}{ll}
$\frac{\text { NT species }}{C m a \quad C m u}$ \\
\hline
\end{tabular}

\section{Likelihood of Encounter (LEnj)}

E1. Proportion of the geographic range of NT species that is included in the predicted geographic range of the exotic $\mathrm{GABCA}^{1}$

E2. Proportion of the season when a vulnerable stage(s) of the NT species is available that occurs when the exotic GABCA is active ${ }^{2}$

E3. Proportion of the habitats (in the E1 geographical range) used by a NT species that are also used by the exotic GABCA or that can be reached by dispersal of the exotic GABCA. ${ }^{3}$

E4. Proportion of plants in habitats used by the NT species that are expected to be searched by the exotic GABCA (niche component). ${ }^{4}$

E5. Likelihood that the non-target species will be found by the exotic GABCA on the plants that it searches (i.e., those plants satisfying E4). ${ }^{5}$

$$
\mathrm{LE} n j=\mathrm{E} 1 j \times \mathrm{E} 2 j \times \mathrm{E} 3 j \times \mathrm{E} 4 j \times \mathrm{E} 5 j
$$

Uncertainty in LEnj: provide a lower and upper bound of LEn $j$ that you believe will give a $95 \%$ credibility interval for these LEn $j$ estimates

Likelihood $(\mathrm{L} j)$ of a short-term effect on non-target species $\boldsymbol{j}$

A1. Likelihood that the exotic GABCA recognizes and attacks the NT species ${ }^{6}$

A2. Likelihood that the exotic GABCA successfully kills (or damages) the nontarget individual (or plant part) after attack (A1). ${ }^{7}$

$$
\mathrm{L} j=\mathrm{A} 1 j \times \mathrm{A} 2 j
$$

Uncertainty in $\mathrm{L} j$ : provide a lower and upper bound of $\mathrm{L} j$ that you believe will give a $95 \%$ credibility interval for these $\mathrm{L} j$ estimates

$$
\text { Lower bound }
$$$$
\text { Upper bound }
$$

\section{Magnitude $(\mathrm{M} j)$ of a short-term effect on non-target species $\boldsymbol{j}$}

These are set to 1 for the case that the exotic GABCA successfully kills (or damages) the NT individual it attacks. This can be modified for other less severe effects, such as trait-mediated effects

$$
\mathrm{M} j=1
$$

\section{Overall short-term effect $^{8}$}

$$
\operatorname{Eff} j=\operatorname{LEn} j \times \mathrm{L} j \times \mathrm{M} j
$$

Uncertainty in Effj

$$
\begin{aligned}
& \text { Lower bound }^{9} \\
& \text { Upper bound }^{10}
\end{aligned}
$$

\section{Valuation (V) of short-term effects}

Legally protected species (endangered, threatened or special concern)

Enter an estimated population size of attacked stage of the species

Enter the degree of threat: endangered $=1$; threatened $=1.5$; special concern $=2$
1.0

1.0

0.90

0.60

0.30

0.16

0.10

0.40

1.0

0.50

0.50

0.30

0.70

0.70 none 


\begin{tabular}{|c|c|c|}
\hline & \multicolumn{2}{|l|}{ NT species } \\
\hline & $\mathrm{Cma}$ & $\mathrm{Cmu}$ \\
\hline \multicolumn{3}{|l|}{ Rare endemic species } \\
\hline \multicolumn{3}{|l|}{$\begin{array}{l}\text { Enter the degree of endemism (proportion of the total land area that is } \\
\text { suitable habitat) }\end{array}$} \\
\hline \multicolumn{3}{|l|}{$\begin{array}{l}\text { Enter the relative population size in the endemic areas (relative to another } \\
\text { endemic species, expressed as a proportion of that species) }\end{array}$} \\
\hline Significance of species (small is more significant) & none & none \\
\hline \multicolumn{3}{|l|}{ or } \\
\hline \multicolumn{3}{|l|}{ All other species } \\
\hline $\begin{array}{l}\text { List why the species is valued (e.g., income, biological control service, } \\
\text { pollination service, culture, etc.) }\end{array}$ & $\begin{array}{c}\text { Biological } \\
\text { control } \\
\text { service }\end{array}$ & $\begin{array}{c}\text { Biological } \\
\text { control } \\
\text { service }\end{array}$ \\
\hline $\begin{array}{l}\text { Significance: estimate how much the Effj for that species would reduce this } \\
\text { value }(1-10 \text { scale, } 1 \text { is } 0-10 \%, 10 \text { is } 90-100 \%) \text {. (large is more significant) }\end{array}$ & 8.00 & 7.00 \\
\hline List the stakeholder(s) who may be harmed by the loss of value & $\begin{array}{l}\text { Soybean } \\
\text { producers }\end{array}$ & $\begin{array}{l}\text { Soybean } \\
\text { producers }\end{array}$ \\
\hline Based on Effj and V, would you select which (if any) & Selected & Not selected \\
\hline
\end{tabular}

\footnotetext{
${ }^{1}$ This can be estimated from maps of the known or predicted geographical distribution of the NT species and exotic GABCA

${ }^{2}$ This is only for the NTs satisfying E1, i.e., in the part of the geographic range where they overlap. This can be estimated by knowing the vulnerable stage of the NT species and when it occurs seasonally relative to the predicted seasonal activity of the exotic GABCA in the region of geographic overlap

${ }^{3}$ This is only for the NTs satisfying E2, i.e., with seasonal overlap with the exotic GABCA. This can be estimated from the habitats used by the NT species (habitats that are both suitable and occupied by the NT) that are also used by the exotic GABCA, and NT habitats that are close enough to GABCA habitats that the exotic GABCA will disperse into the NT habitat. The NT and GABCA may overlap geographically and temporally, but if they do not use the same habitat, they will not encounter each other

${ }^{4}$ This is only for habitats satisfying E3. For NT plants, the likelihood that the exotic GABCA will find the plant in the habitats satisfying E3. For NT plants, this can be estimated approximately from the proportion of NT plants in the habitat. For NT species on plants, this can be estimated from the proportion of plants used by the NT species in the habitat, assuming random search by the exotic GABCA. If the exotic GABCA prefers these plants the proportion will be higher than random, and if it disprefers these plants, the proportion will be lower. For weed-free monocultures, this parameter might be 1, but for vegetationally diverse habitats, it might be much less than 1

${ }^{5}$ This parameter is valid only for non-plant NTs. This niche component should be considered for the entire vulnerable stage of the NT species assuming that the exotic GABCA does search a plant that has the NT species. This score will be affected by the expected density of exotic GABCA, how rapidly the NT species can be found, and how rapidly the exotic GABCA leaves the plant before finding it. Several factors may affect this likelihood, such as non-target characteristics that make it highly accessible (e.g., release attractive semiochemicals) or inaccessible (e.g., hiding, feeding on a plant part that the exotic GABCA does not search) to the exotic GABCA. Inaccessible species will have a likelihood near 0

${ }^{6}$ Encounter does not always result in attack. Attack is affected by: (1) Presence or absence of NT defense behaviors or characteristics that reduce attack rates (e.g., crypsis, aposematic coloration, hardness of chorion or cuticle, kicking, dropping, removing host/prey location cues used by the exotic GABCA, irritating regurgitant, toxic reflex bleeding, etc.). (2) For NT plants, characteristics that make the plant easy (e.g., semiochemicals that call in the GABCA) or hard (e.g., repellent semiochemicals, occurence in microhabitats [shade, sun, aspect] not normally searched by the GABCA) to find for the exotic GABCA

${ }^{7}$ Many attacks of predators fail. For an exotic GABCA parasitoid, this can be reduced by host physiological defenses, such as encystment and encapsulation

${ }^{8}$ This can be modified for other less severe effects, such as trait-mediated effects

${ }^{9,10}$ Multiplication of all the lower and upper bounds and $\mathrm{M} j$, respectively
} 
short-term effects are then evaluated to determine if any are large enough to require additional testing.

The short-term effect of an exotic GABCA on a non-target species $j$ in category of effect $i$ (Effij) is assessed by independently estimating the:

- Likelihood of encounter (LEnij) between the exotic GABCA with the non-target species $j$, which is determined from geographic, temporal, habitat and niche use overlap.

- Likelihood (Lij) of an effect on non-target species $j$, which is the probability of successful attack or interaction.

- Magnitude (Mij) of an effect on non-target species $j$ after encounter, which is the consequence of the attack or interaction.

These estimates are combined (Table 4) to estimate an overall short-term effect on a non-target species $j$ as follows.

Eff $i j=\mathrm{LE} n i j \times \mathrm{L} i j \times \mathrm{M} i j$

Quantitative data, if they exist, should be used to estimate any of those components of the risk. Otherwise, estimates should be based on expert judgments. This is similar to stepwise approaches in ERA in many fields, including biological control (Andow et al. 1995; Olckers 2003).

Large Effij are not automatically more significant than small ones, because significance depends on their value to society. Valuations are used to determine which species, if any, should be selected as a test species in the final part of the Definitive Assessment (Table 4). For each non-target species $j$, the short-term effects $\left(\mathrm{Eff}_{j}\right)$ are used to determine relative valuations to make them comparable across the species and facilitate the selection process. Values include reduction in ecosystem services, erosion of biodiversity, cultural, symbolic, aesthetic, or income values, and harm to protected species. All of these values require a human agent/stakeholder who is harmed by the loss of value, as specified in the Screening Assessment (Table 2). This implies that valuations may differ amongst jurisdictions. In the interest of environmental justice, effects on stakeholders who lack power, legitimacy and urgency may be valued more highly than those with power, legitimacy and urgency (Mitchell et al. 1997).

Valuation relies on both the value of the species that could be affected and the size of the short-term effect on that species. Valuation of rare species (e.g., endangered, threatened, and rare endemics) is based on the desire to preserve such species. Hence, all other things being equal, the rarer the species and the greater the effect of the GABCA (Eff $j$ ), the greater is the need to protect the species against effects by the exotic GABCA, and the higher is its value. If the number of individuals harmed is predicted to be very small (such as less than the fecundity of a single female) and the number is predicted to be a small part of the population (such as less than $0.1 \%$ of the population), then such a species would probably not need to be selected for additional testing. Such a small effect would be very difficult to measure precisely enough to determine that an exotic GABCA would actually adversely affect the rare species. For legally protected species (endangered, threatened or special concern) and some rare endemics where there is a population size estimate (available in the documentation supporting the original listing or the recovery plan), this estimate can be used to evaluate the relative rarity and potential severity of Effj. For most rare endemics, population estimates are not available, so relative rarity should be estimated, perhaps by comparison with another, better known endemic.

Valuation of all other species in the remaining categories of potential adverse effect is based on identifying the value, assessing the relative impact of Eff $j$ on that value and identifying the stakeholder(s) who may be harmed by the reduction in value. There are many possible economic and environmental values that a non-target species may contribute, including pollination, biological control, biodiversity value, cultural values (beliefs, traditions, rituals), symbolic value, aesthetic value, and income value. The value(s) that the non-target species contributes is important to identify so that it is possible to make a concrete assessment of the significance of Eff $j$. To assess significance, estimate how much the Eff $j$ would reduce the value, using a 1-10 scale (1 is $0-10 \%$ reduction in value, 10 is $90-100 \%$ reduction in value). Lastly, identify the stakeholder(s) who may be harmed by this reduction in value. The regulatory authority may wish to consider stakeholder salience to value some non-target species more than others. Stakeholder salience is the prominence of stakeholders to an issue and is based on power, legitimacy and urgency. Highly salient stakeholders have the power to affect the issue, are recognized by others as having a 


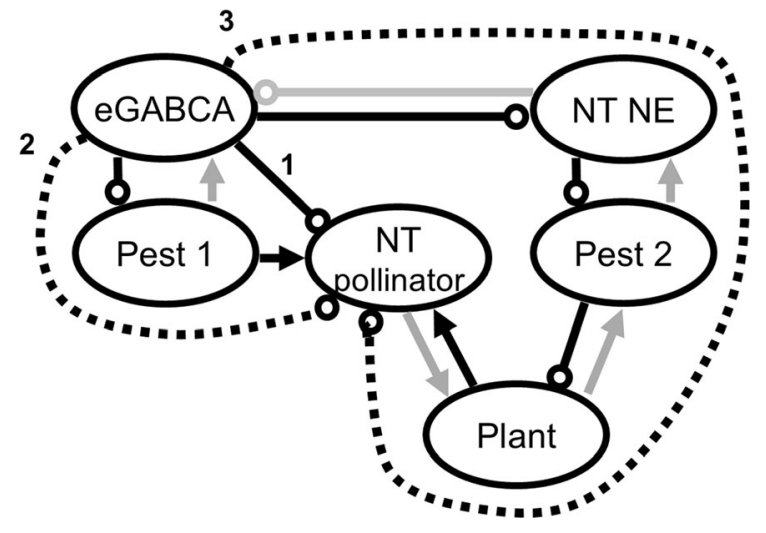

Fig. 5 Some possible pathways by which an exotic GABCA (eGABCA) could affect a non-target (NT) pollinator. (1) eGABCA directly adversely affects NT pollinator, by consuming it or disrupting its behavior. (2) eGABCA indirectly adversely affects NT pollinator by suppressing Pest 1 , which had facilitated the NT pollinator, possibly by the release of semiochemicals that attracted the NT pollinator. (3) eGABCA indirectly adversely affects NT pollinator via another natural enemy (NT NE), releasing Pest 2, which suppresses the Plant. Black solid lines are direct effects involved in the pathways. Gray solid lines are other direct effects. Dotted lines are indirect effects. Arrow represent positive interactions and circles represent negative interactions, using the notation of Puccia and Levins (2013)

legitimate interest or concern in the issue, and have an urgent need to address the issue. The regulatory authority may choose to value high and/or low salience (and uncertainty therein) as a part of the valuation process.

Finally, at the end of the NT form, each expert should select the non-target species (if any) for further assessment through risk quantification keeping in mind that parameters equal to zero or close to zero means the risk is zero or close to zero. During the discussion forums, 16 experts completed the NT form using familiar exotic GABCAs and NT species, illustrating a range of cases from no to all NT species selected for further assessment (forum 4 in Supplementary Material). It is possible that the short-term effects on all of the species in all of the categories are considered too insignificant to merit risk quantification. In this case, the exotic GABCA can be considered by the regulator highly unlikely to have a significant adverse effect on the environment for all categories of effects. Otherwise, the risk(s) in which a category(ies) of effect(s) had a species identified as potentially significantly affected need to be quantified to enable a final regulatory decision. Data to quantify the risk(s) associated with the non-target species should be provided to support assessment and measurement endpoint(s), an analysis model, and the need for gathering any further data, as follows.

Specifying the mechanistic pathway(s) of adverse effect(s)

To enable quantitative evaluation of the risk to the non-target effects that remain, the pathway(s) by which the effect is expected to occur should be specified. This guides the quantification as the strength of the pathway(s) is an important component of the risk, because the risk is the product of the strength of the pathway(s) and the effect of the pathway(s) on the non-target population(s). The pathways can be specified with the ecological interactions between the exotic GABCA and the non-target species (Puccia and Levins 2013). An example of three possible pathways by which an exotic GABCA could affect a non-target pollinator are shown in Fig. 5.

\section{Assessment and measurement endpoints}

An assessment endpoint must be proposed for risk quantification. One logical assessment endpoint for long-term effects on a non-target population is the predicted reduction in the long-term population size by the exotic GABCA. However, other endpoints for the long-term effect on a non-target population and indirect ecosystem effects could be proposed with sufficient justification. A measurement endpoint could be the same as the assessment endpoint, or it could be, for example, other population dynamics parameters that are related to the long-term population size.

\section{Risk quantification analysis plan}

Several possibilities could be considered to enable risk quantification for the non-target species identified:

A. Based on expert recommendations, the regulatory agency could, for each category of effect, suggest experiments, tests and/or models that could be used to assess long-term population effects and indirect ecosystem effects, as partially exemplified in Table 5.

B. Long-term population effects could be evaluated comparatively, i.e. compare with a similar non- 
Table 5 Suggestions of experiments, tests and/or models to assess some indirect ecosystem effects for risk quantification in the Definitive Assessment for exotic generalist arthropod biological control agents (GABCAs)

\begin{tabular}{ll}
\hline Indirect effect & Test \\
\hline Behavioral/evolutionary changes & Laboratory tests (literature review), biology of GABCAs (or related surrogates) \\
\hline $\begin{array}{l}\text { Change in species richness and/or abundance/ } \\
\text { evenness }\end{array}$ & $\begin{array}{l}\text { Laboratory tests (e.g., competition) } \\
\text { Computer modelling (e.g., food webs to identify species at risk) } \\
\text { Potential distribution maps (accounting for climate change) }\end{array}$ \\
\hline Nutrient cycling & Literature review on decomposers \\
\hline Reduced insecticide/herbicide use & $\begin{array}{l}\text { Likelihood of establishment and impact on target sampling (pheromone/sticky } \\
\text { trap) }\end{array}$ \\
Compare to other releases \\
Area of origin comparison (food webs)
\end{tabular}

target species for which the population effect is known from the same or similar exotic GABCA. This may require the availability of a database of known effects.

C. Long-term population effects could be evaluated using models, involving intrinsic growth rates and density dependence (Barlow et al. 2004). This approach has the advantage of being able to account for compensatory mortality.

D. Long-term population effects and indirect ecosystem effects could be evaluated by an expert panel using expert solicitation methods as has been conducted in other ERAs (e.g., Harris et al. 1994).

In cases where a valued species is at risk, additional information may be provided, including: (1) a mitigation proposal to offset the adverse effects, (2) data to show that the exotic GABCA does not suppress the valued species, (3) comparative results to demonstrate that the exotic GABCA has a lower effect on the valued species than the current methods or products on the market, and/or (4) analyses to show that not using the exotic GABCA has greater risk on the valued species than using the exotic GABCA.

The use of surrogate species might be appropriate instead of the actual non-target species when: (1) nontarget at risk species are threatened, endangered or rare endemic; (2) the experiments themselves would jeopardize the species; (3) if the ERA is performed in the native range of the exotic GABCA; or (4) it is very difficult or impossible to test the actual non-target species. The criteria for a species to be selected as a surrogate are all of the following: is taxonomically close (same genus) to the non-target species, has functionally similar ecologies, uses the same habitat, is a common species, is relevant to the receiving environment, is well-studied taxon, is easy to rear. The use of surrogates must be determined on a case-bycase basis in consultation with the regulatory authority.

\section{Closure of the ERA}

The requested data for risk quantification are submitted to the regulatory agency. The regulatory agency conducts the final risk characterization with technical input from experts on a case-by-case basis, i.e. this time with no pre-established risk threshold. The regulatory agency will complete its assessment process (e.g., after public comment or public hearing) and determine an outcome which could be to: approve the petition, approve the petition with conditions, not approve/decline the petition or request further information.

\section{An improved ERA?}

The three-tiered ERA outlined in this paper could support the regulatory system in many countries as it would facilitate a transparent, scientific approach to assessing the risks of exotic GABCAs on a case-bycase basis. It expands on the scoping assessment originally proposed by van Lenteren et al. (2003) and the two-tiered method recently published by EPPO (2018), implementing major improvements. First, the 
three tiers provide several opportunities to use published information and expert judgement to provide upper bounds on the potential risks of introducing or commercially releasing an exotic GABCA before additional data are needed, and focus these data collecting activities on the most critical issues. Our Scoping Assessment differs from the van Lenteren et al. (2003) and EPPO (2018) approach by evaluating the possible existence of risks instead of likely risk. If risks might exist, then additional assessment is required, while under the previous scoping assessments, risks must be judged to be likely to require additional assessment. The present Scoping Assessment entails biosafety questions with greater specificity and rigor, and it results in a more riskaverse determination than previous methods. It includes all of the elements of the EPPO (2018) express EIA, except the EPPO (2018) explicitly considers the balance between benefits and risks, and considers an exotic BCA highly unlikely to have a significant adverse effect on the environment if the benefits are likely to "significantly" exceed the risks. Our method allows consideration of a risk-benefit balance, but does not specify how this balance would affect the acceptability of risk.

Second, the present methodology uses categories of effects to guide the ERA instead of considering risks to any non-target species. The 19 categories of effects (Table 2) are the documented ways an exotic BCA can affect the environment. They enable a comprehensive evaluation of potential environmental risks in the Scoping and Screening Assessments without requiring a detailed evaluation of specific risks to specific nontarget species. As most exotic BCAs will affect only a relatively small subset of these 19 categories, this focuses subsequent steps in the ERA on issues of greatest concern. It also delays identification of potential at risk species until much later in the ERA, avoiding some unneeded work to compile comprehensive species lists that might be affected (e.g., Kuhlmann et al. 2006) by focusing only on compiling lists of those species associated with the important categories of risk(s). This approach divides the process of non-target species identification developed by Todd et al. (2015) into two parts, one associated with the categories of effects and another associated with the prioritization and identification of non-target species within a category. Finally, this approach implies that not all host/prey are considered at risk, as an effect on some of these host/prey may not be considered significant enough to merit additional assessment. This may occur because the species itself has low social value or because the effect is considered insignificant, such as the effect of augmentative releases of Trichogramma nubilale Ertle \& Davis 1975 (Hymenoptera: Trichogrammatidae) on the endangered Karner blue butterfly (Lycaeides melissa samuelis (Nabokov 1944) (Lepidoptera: Lycaenidae), Andow et al. 1995) or T. brassicae Bezdenko 1968 on native Lepidoptera and the parasitoid Lydella thompsoni Herting, 1959 (Diptera: Tachinidae) (Lynch et al. 2001).

Third, the methodology offers explicit methods to analyze the potential effects of an exotic GABCA on non-target species. In the Screening Assessment, these are based on the semi-quantitative analysis of expert judgements of the likelihood and magnitude of an adverse effect via an interaction characterized by the category of effect. For example, for an effect on a nontarget species via exploitative competition, the likelihood is the probability that the exotic GABCA and non-target species will occur together, and the magnitude is the size of the effect the exotic GABCA might have on the non-target assuming that they cooccur. In the species selection process of the Definitive Assessment, likelihood and magnitude are estimated quantitatively. The likelihood of co-occurrence is separated into spatial overlap, temporal overlap, habitat overlap, niche overlap, and likelihood of encounter in the niche. The magnitude of the effect is the reduction in survival and/or reproduction of an individual non-target species, if it co-occurs with the exotic BCA. By breaking down the adverse effect into its components, it is possible to construct an estimate while at the same time reveal knowledge gaps.

Fourth, it introduces in the Screening and Definitive Assessments an explicit reliance on the social valuation of adverse effects. Although there is considerable variation in how to value individual species, valuation is essentially a social process. That is, the social significance of an adverse effect should be considered when determining the significance of an adverse effect. For example, a $20 \%$ long-term reduction in the population of some common non-target arthropod herbivore might not be considered socially significant if the non-target will still be common and is not endangered. 
As several countries and jurisdictions allow a comparison of risks and benefits of proposed introductions of exotic BCAs, methods to incorporate a formal assessment of benefits still needs to be developed. In our Scoping Assessment, risks may be poorly characterized and highly uncertain compared to benefits, so a simple risk-benefit comparison might not be appropriate, as it may favor the more certain benefits over the highly uncertain risks. In addition, there may be trade-offs that would need to be taken into consideration where, for example, the economic benefits are maybe substantial if the exotic BCA provides significant pest control. In the Screening Assessment, the semi-quantitative assessments of benefits and risks may be difficult to compare. They are based on ordinal scales that may not be directly comparable, so methods to weigh the benefits and risks are needed.

We recognize that this is a conceptual proposal for an improved ERA for all exotic BCAs, including GABCAs. Although the expert panel agreed that it is based on sound scientific principles, its practicality for both regulators and applicants requires testing against other species in novel environments. It would be useful to conduct several case studies to reveal ambiguities and generate estimates of the cost of the tiers and the time it takes to complete them. Furthermore, it is essential to involve the regulatory community and potential applicants, perhaps initially to suggest relevant case studies, and thereafter to evaluate the results. This proposed ERA for exotic GABCAs, and other BCAs, aims to enable evaluation of their environmental safety, while focusing greater efforts on their specific risks needing greater oversight, rigorously and without prejudice. We hope these efforts provide a pathway for the assessment and possible approval for the safe use of exotic GABCAs and other BCAs.

Acknowledgements We are grateful for all the experts and stakeholders worldwide who contributed to this work. We thank Embrapa (grant number SEG 12.13.12.005.00.00), USDA (NIFA grant 2019-67013-29406) and the New Zealand Better Border Biosecurity Research Collaboration for their financial support.

\section{Compliance with ethical standards}

Conflict of interest The authors declare that they have no conflict of interest.

\section{References}

Andow DA, Lane CP, Olson DM (1995) Use of Trichogramma in maize-estimating environmental risks. In: Lynch JM, Hokkanen $\mathrm{HH}$ (eds) Benefits and risks of introducing biocontrol agents. Blackwell, London, pp 101-118

Andreassen LD, Kuhlmann U, Mason PG, Holliday NJ (2009) Host range testing of a prospective classical biological control agent against cabbage maggot, Delia radicum, in Canada. Biol Control 48:210-220

Arthurs S, McKenzie CL, Chen J, Doğramaci M, Brennan M, Houben K, Osborne L (2009) Evaluation of Neoseiulus cucumeris and Amblyseius swirskii (Acari: Phytoseiidae) as biological control agents of chilli thrips, Scirtothrips dorsalis (Thysanoptera: Thripidae) on pepper. Biol Control 49:91-96

Barlow ND, Barratt BIP, Ferguson CM, Barron MC (2004) Using models to estimate parasitoid impacts on non-target host abundance. Environ Entomol 33:941-948

Barratt BIP, Todd J, Malone LA (2016) Selecting non-target species for arthropod biological control agent host range testing: evaluation of a novel method. Biol Control 93:84-92

Bigler F, Babendreier D, Kuhlmann U (2006) Environmental impact of invertebrates for biological control of arthropods: methods and risk assessment. CAB International, Wallingford

Carmichael AC, Wharton RA, Clarke AR (2005) Opiine (Hymenoptera: Braconidae) parasitoids of tropical fruit flies (Diptera: Tephritidae) of the Australian and South Pacific region. Bull Entomol Res 95:545-569

Castañé C, Arnó J, Gabarra R, Alomar O (2011) Plant damage to vegetable crops by zoophytophagous mirid predators. Biol Control 59:22-29

Cédola C, Polack A (2011) First record of Amblyseius swirskii (Acari: Phytoseiidae) from Argentina. Rev Soc Entomol Arg 70:375-378

Cock MJW, Murphy ST, Kairo MTK, Thompson E, Murphy RJ, Francis AW (2016) Trends in the classical biological control of insect pests by insects: an update of the BIOCAT database. BioControl 61:349-363

EPA (New Zealand) (2013) Application to import for release or to release from containment new organisms, Macrolophus pygmaeus, application APP201254, 2013 November 20. https:/www.epa.govt.nz/assets/FileAPI/hsno-ar/ APP201254/APP201254-EPA-BCA-applicationMacrolophus-2013-FINAL.pdf. Accessed 6 Feb 2019

EPA (New Zealand) (2014) EPA decision for application APP201254, 2014 April 17. https://www.epa.govt.nz/ assets/FileAPI/hsno-ar/APP201254/APP201254-

APP201254-Decision-FINAL-2014-04-17.pdf. Accessed 6 Feb 2019

EPPO (European and Mediterranean Plant Protection Organization) (2018) PM 6/04 (1) decision-support scheme for import and release of biological control agents of plant pests. EPPO Bull 48:352-367

EPPO (2020) PM 6/3(4) List of biological control agents widely used in the EPPO region-2020 version. https://www. eppo.int/media/uploaded_images/RESOURCES/eppo_ 
standards/pm6/pm6-03-2020-en.pdf. Accessed 12 Sept 2020

Harris HJ, Wegner RB, Harris VA, Devault DS (1994) A method for assessing environmental risk: a case study of Green Bay, Lake Michigan, USA. Environ Manag 18:295-306

Holler TC, Gerónimo F, Sivinski J, Gonzalez JC, Stewart J (1996) Mediterranean fruit fly parasitoid aerial release test in Guatemala. In: $2^{\circ}$ WGFFWH meeting, Viña del Mar, Chile, pp 74-75

Hopper KR (2001) Research needs concerning non-target impacts of biological control introductions. In: Wajnberg E, Scott JK, Quimby PC (eds) Evaluating indirect ecological effects of biological control. CAB International, Wallingford, pp 39-56

Kade N, Gueye-Ndiaye A, Duverney C, Moraes GJ (2011) Phytoseiid mites (Acari: Phytoseiidae) from Senegal. Acarologia 51:133-138

Kuhlmann U, Schaffner U, Mason PG (2006) Selection of nontarget species for host specificity testing of entomophagous biological control agents. In: Second international symposium on biological control of arthropods, Davos, Switzerland, pp 12-16

Kynn M (2008) The 'heuristics and biases' bias in expert elicitation. J R Stat Soc A 171:239-264

Le Hesran S, Ras E, Wajnberg E, Beukeboom L (2019) Next generation biological control-an introduction. Entomol Exp Appl 167:579-583

Lynch LD, Hokkanen HMT, Babendreier D, Bigler F, Burgio G, Gao ZH, Kuske S, Loomans A, Menzler-Hokkanen I, Thomas MB, Tommasini G, Waage JK, van Lenteren JC, Zeng QQ (2001) Insect biological control and non-target effects: a European perspective. In: Wajnberg E, Scott JK, Quimby PC (eds) Evaluating indirect ecological effects of biological control. CAB International, Wallingford, pp 99-125

McGrath Z, MacDonald F, Walker G, Ward D (2020) A framework for predicting competition between native and exotic hymenopteran parasitoids of lepidopteran larvae using taxonomic collections and species level traits. BioControl. https://doi.org/10.1007/s10526-020-10025-y

McMurtry JA, De Moraes GJ, Sourassou NF (2013) Revision of the lifestyles of phytoseiid mites (Acari: Phytoseiidae) and implications for biological control strategies. Syst Appl Acarol 18:297-320

Messing R, Roitberg B, Brodeur J (2006) Measuring and predicting indirect impacts of biological control: competition, displacement and secondary interactions. In: Bigler F, Babendreier D, Kuhlmann U (eds) Environmental impact of invertebrates for biological control of arthropods: methods and risk assessment. CAB International, Wallingford, pp 64-77

Mitchell R, Agle B, Wood D (1997) Toward a theory of stakeholder identification and salience: defining the principle of who and what really counts. Acad Manag Rev 22:853-886

Morgan MG (2014) Use (and abuse) of expert elicitation in support of decision making for public policy. PNAS 111:7176-7184

NAPPO (2015) RSPM 12 Guidelines for petition for first release of non-indigenous entomophagous biological control agents. The Secretariat of the North American Plant Protection Organization, Ottawa, p 14

Nechols JR, Kauffman WC, Schaefer PW (1992) Significance of host specificity in classical biological control. In: Kauffman WC, Nechols JR (eds) Selection criteria and ecological consequences of importing natural enemies. Thomas Say Publications in Entomology, Entomological Society of America, Lanham, pp 41-52

O'Hagan A (2005) Research in elicitation. Department of Probability and Statistics, School of Mathematics, University of Sheffield, Sheffield

Olckers T (2003) Assessing the risks associated with the release of a flowerbud weevil, Anthonomus santacruzi, against the invasive tree Solanum mauritianum in South Africa. Biol Control 28:302-312

Ovruski S, Aluja M, Sivinski J, Wharton R (2000) Hymenopteran parasitoids on fruit-infesting Tephritidae (Diptera) in Latin America and the southern United States: diversity, distribution, taxonomic status and their use in fruit fly biological control. J Integr Pest Manag 5:81-107

Paula DP, Linard B, Platt AC, Srivathsan A, Timmermans MJTN, Sujii ER, Pires CSS, Souza LM, Andow DA, Vogler AP (2016) Uncovering trophic interactions in arthropod predators through DNA shotgun-sequencing of gut contents. PLoS ONE 11(9):e0161841

Pedrycz W, Gomide F (2007) Fuzzy systems engineering: toward human-centric computing. Wiley, New York

Petit JN, Hoddle MS, Grandgirard J, Roderick GK, Davies N (2009) Successful spread of a biocontrol agent reveals a biosecurity failure: elucidating long distance invasion pathways for Gonatocerus ashmeadi in French Polynesia. BioControl 54:485-495

Puccia CJ, Levins R (2013) Qualitative modeling of complex systems: an introduction to loop analysis and time averaging. Harvard University Press, Cambridge

Rahman MM (2016) Multiplication and division of triangular fuzzy numbers. DIU J Sci Technol 11(2):49-53

Rousse P, Harris EJ, Quilici S (2005) Fopius arisanus, an eggpupal parasitoid of Tephritidae - an overview. Biocontrol News Info 26:59-69

Roy HE, Brown PM, Adriaens T, Berkvens N, Borges I, Clusella-Trullas S, Comont RF, De Clercq P, Eschen R, Estoup A, Evans EW, Facon B, Gardiner MM, Gil A, Grez AA, Guillemaud T, Haelewaters D, Herz A, Honek A, Howe AG, Hui C, Hutchison WD, Kenis M, Koch RL, Kulfan J, Handley LL, Lombaert E, Loomans A, Losey J, Lukashuk AO, Maes D, Magro A, Murray KM, Martin GS, Martinkova Z, Minnaar IA, Nedved O, Orlova-Bienkowskaja MJ, Osawa N, Rabitsch W, Ravn HP, Rondoni G, Rorke SL, Ryndevich SK, Saethre M-G, Sloggett JJ, Soares AO, Stals R, Tinsley MC, Vandereycken A, van Wielink P, Viglášová S, Zach P, Zakharov IA, Zaviezo T, Zhao Z (2016) The harlequin ladybird, Harmonia axyridis: global perspectives on invasion history and ecology. Biol Invasions 18:997-1044

Sackman H (1974) Delphi assessment: expert opinion, forecasting, and group process (no. RAND-R-1283-PR). Rand Corp, Santa Monica

Sands DPA, van Driesche RG (2004) Using the scientific literature to estimate the host range of a biological control agent. In: van Driesche RG, Sands DPA (eds) Assessing 
host ranges of parasitoids and predators used for classical biological control: a guide to best practice. Forest Health Technology Enterprise Team, Forest Service, USDA, Morgantown, pp 15-23

Sato Y, Mochizuki A (2011) Risk assessment of non-target effects caused by releasing two exotic phytoseiid mites in Japan: can an indigenous phytoseiid mite become IG prey? Exp Appl Acarol 54:319-329

Snyder WE, Evans EW (2006) Ecological effects of invasive arthropod generalist predators. Annu Rev Ecol Evol Syst 37:95-122

Stahl J, Tortorici F, Pontini M, Bon M-C, Hoelmer K, Marazzi C, Tavella L, Haye T (2019) First discovery of adventive populations of Trissolcus japonicus in Europe. J Pest Sci 92:371-379

Todd JH, Barratt BIP, Tooman L, Beggs JR, Malone LA (2015) Selecting non-target species for risk assessment of entomophagous biological control agents: evaluation of the PRONTI decision-support tool. Biol Control 80:77-88

van Lenteren JC, Babendreier D, Bigler F, Burgio G, Hokkanen HMT, Kuske S, Loomans AJM, Menzler-Hokkanen I, van Rijn PCJ, Thomas MB, Tommasini MG, Zeng QQ (2003) Environmental risk assessment of exotic natural enemies used in inundative biological control. BioControl 48:3-38

van Lenteren JC, Bale J, Bigler F, Hokkanen HMT, Loomans AJM (2006) Assessing risks of releasing exotic biological control agents of arthropod pests. Annu Rev Entomol 51:609-634

van Lenteren JC (2012) The state of commercial augmentative biological control: plenty of natural enemies, but a frustrating lack of uptake. BioControl 57:1-20

van Lenteren JC, Bolckmans K, Köhl J, Ravensberg WJ, Urbaneja A (2018) Biological control using invertebrates and microorganisms: plenty of new opportunities. BioControl 63:39-59 van Lenteren JC, Bueno VH, Colmenarez YC, Luna MG (2020) Biological control in Latin America and the Caribbean: its rich history and bright future. CAB International, Wallingford, p 522

Vanderhoeven S, Branquart E, Casaer J, Dhondt B, Hulme PE, Shwartz A, Strubbe D, Turbé A, Verreycken H, Adriaens T (2017) Beyond protocols: improving the reliability of expert-based risk analysis underpinning invasive species policies. Biol Invasions 19:2507-2517

Vargas RI, Stark JD, Uchida GK, Purcell M (1993) Opiine parasitoids (Hymenoptera: Braconidae) of Oriental fruit fly (Diptera: Tephritidae) on Kauai Island, Hawaii: Islandwide relative abundance and parasitism rates in wild and orchard guava habitats. Environ Entomol 22:246-253

Vargas RI, Leblanc L, Putoa R, Eitam A (2007) Impact of introduction of Bactrocera dorsalis (Diptera: Tephritidae) and classical biological control releases of Fopius arisanus (Hymenoptera: Braconidae) on economically important fruit flies in French Polynesia. $J$ Econ Entomol 100:670-679

Wang XG, Bokonon-Ganta AH, Ramadan MM, Messing RH (2004) Egg-larval opiine parasitoids (Hym., Braconidae) of tephritid fruit fly pests do not attack the flowerhead-feeder Trupanea dubautiae (Dipt., Tephritidae). J Appl Entomol 12:716-722

Waterhouse DF (1993) Pest fruit flies in the Oceanic Pacific. In: Waterhouse DF (ed) Biological control: Pacific prospects-supplement 2. Australian Centre for International Agricultural Research, Canberra, pp 4-47

Wyckhuys KA, Lu Y, Morales H, Vazquez LL, Legaspi JC, Eliopoulos PA, Hernandez LM (2013) Current status and potential of conservation biological control for agriculture in the developing world. Biol Control 65:152-167 